\title{
Pressure Infiltration of Molten Aluminum for Densification of Environmental Barrier Coatings
}

\section{Lin Dong}

State Key Laboratory for Mechanical Behavior of Materials, School of Materials Science and Engineering, Xi'an Jiaotong University, Xi'an, Shaanxi 710049, PR China

Mei-Jun Liu ( $\square$ liumjun@mail.xjtu.edu.cn )

State Key Laboratory for Mechanical Behavior of Materials, School of Materials Science and Engineering, Xi'an Jiaotong University, Xi'an, Shaanxi 710049, PR China

\section{Xiaofeng Zhang}

Institute of New Materials, Guangdong Acadamy of Science

\section{Xueshi Zhuo}

Institute of New Materials, Guangdong Academy of Science

\section{Jiafeng Fan}

Institute of New Materials, Guangdong Academy of Science

\section{Guan-Jun Yang}

Xi'an Jiaotong University https://orcid.org/0000-0002-7753-3636

\section{Kesong Zhou}

Institute of New Materials, Guangdong Acadamy of Science

\section{Research Article}

Keywords: infiltration process, channel pore, densification, pressure assistant, environmental barrier coating (EBC)

Posted Date: April 16th, 2021

DOI: https://doi.org/10.21203/rs.3.rs-416196/v1

License: (c) (i) This work is licensed under a Creative Commons Attribution 4.0 International License. Read Full License

Version of Record: A version of this preprint was published at Journal of Advanced Ceramics on November 10th, 2021. See the published version at https://doi.org/10.1007/s40145-021-0523-9. 


$$
\text { Dr. Mei-Jun Liu }
$$

State Key Laboratory for Mechanical Behavior of Materials

School of Materials Science and Engineering, Xi'an Jiaotong University

Xi'an Shaanxi, 710049, P. R. China

Tel: ++86-29-82665299; Fax: ++86-29-83237910

E-mail: liumjun@mail.xjtu.edu.cn

\section{Dr. Xiao-Feng Zhang}

National Engineering Laboratory for Modern Materials Surface Engineering Technology Institute of New Materials, Guangdong Academy of Science

Guangzhou, 510650, P. R. China

E-mail: zxf200808@126.com

April 6, 2021

Dear Editor,

We would like to submit our manuscript entitled "Pressure infiltration of molten aluminum for densification of environmental barrier coatings" to be considered for publication in Journal of Advanced Ceramics.

This work proposed a post-treatment approach for densification of environmental barrier coatings (EBCs), that is, through pressure assistance, filled and blocked open channels with molten aluminum to prevent the oxidants and corrosives in the harsh engine environment from being transported to SiC ceramic matrix composites (SiCCMCs) substrate. Results showed that infiltration behavior was determined by pressure conditions and pore geometry, and their mathematical relationships were established. There is a critical pressure value to assist the full infiltration in each known geometry. Finally, a thick and dense protective film was obtained just by adjusting the gas pressures. It is of meaningful guidance for melt infiltration in irregular channels whether in coatings or substrates to obtain dense structure.

This manuscript is our original unpublished work and it has not been submitted to any other journal for review. We have read and understood your journal's policies, and we believe that neither the manuscript nor the study violates any of them. There are no conflicts of interest to declare. Thank you very much for your kind consideration.

Sincerely yours,

Mei-Jun Liu, Xiao-Feng Zhang 


\section{Pressure infiltration of molten aluminum for densification of environmental barrier coatings}

Lin Dong ${ }^{1}$, Mei-Jun Liu ${ }^{1 *}$, Xiaofeng Zhang ${ }^{2 *}$, Xueshi Zhuo², Jiafeng Fan², Guan-Jun Yang ${ }^{1}$, Kesong Zhou ${ }^{2}$

${ }^{1}$ State Key Laboratory for Mechanical Behavior of Materials, School of Materials Science and Engineering, Xi'an Jiaotong University, Xi'an, Shaanxi 710049, PR China

${ }^{2}$ National Engineering Laboratory for Modern Materials Surface Engineering Technology, Institute of New Materials, Guangdong Academy of Science, Guangzhou, 510650, PR China

*: Corresponding author 1: Dr. Mei-Jun Liu

State Key Laboratory for Mechanical Behavior of Materials

School of Materials Science and Engineering, Xi' an Jiaotong University

Xi'an Shaanxi, 710049, P. R. China

Tel: ++86-29-82665299;

Fax: ++86-29-83237910

E-mail: liumjun@mail.xjtu.edu.cn

Corresponding author 2: Dr. Xiaofeng Zhang

National Engineering Laboratory for Modern Materials Surface Engineering Technology

Institute of New Materials, Guangdong Academy of Science

Guangzhou, 510650, P. R. China

E-mail: zxf200808@126.com 


\begin{abstract}
Environmental barrier coatings (EBCs) effectively protect ceramic matrix composites (CMCs) from harsh engine environment, especially steam and molten salts. However, open pores inevitably formed during deposition process provide transport channels for oxidants and corrosives and lead to premature failure of EBCs. This work proposed a pressure infiltration densification method that blocked these open pores in the coatings. Results showed that it was difficult for aluminum to infiltrate spontaneously, but with the increase of external gas pressure and internal vacuum simultaneously, the molten aluminum obviously moved forward, but finally stopped infiltrating at a depth of a specific geometry. Based on the wrinkled zigzag pore model, a mathematical relationship between the critical pressure and the infiltration depth and the pore intrinsic geometry was established. Infiltration results confirmed this relationship, indicating that for a given coating, a dense thick film can be obtained by adjusting the internal and external gas pressures to drive the melt infiltration.
\end{abstract}

Keywords: infiltration process, channel pore, densification, pressure assistant, environmental barrier coating $(\mathrm{EBC})$

\title{
1. Introduction
}

With the increasing demand for high operating temperature of new gas-turbine engines, SiC-based ceramic matrix composite ( $\mathrm{SiC}-\mathrm{CMC}$ ) materials have attracted great interest for their high-temperature tolerance, superior mechanical properties, low density [1-4]. Under the combustion environment of an engine, which contains heated steam or corrosives (such as sand and volcanic ash, generally known as CMAS), SiC-CMC materials suffer from severe degradation, especially for the accelerated oxidation induced by steam [5-11]. To prevent the deleterious environmental attack of $\mathrm{SiC}$ components, environmental barrier coatings (EBCs) were developed to cover the $\mathrm{SiC}$ surface. The candidate materials for $\mathrm{EBC}$ are expected to fulfill a set of requirements [4, 12-14], such as high-temperature phase stability, similar thermal expansion coefficient (CTE) to the matrix, chemical compatibility, steam stability, and CMAS corrosion resistance. 
Ytterbium monosilicate $\left(\mathrm{Yb}_{2} \mathrm{SiO}_{5}, \mathrm{YbMS}\right)$ was approved to be a promising candidate for EBCs for its non-phase transformations and low silica activity during high-temperature service [15-18]. Nevertheless, a CTE mismatch between the top layer and the substrate is presented, which induced thermal stresses and the appearance of vertical pores or cracks [17-20]. As a result, these pores cross-linked together and forming complex networks [8, 21, 22]. Although these pores endow the excellent stress tolerance of coatings, steam and other corrosives infiltrate from the openings and cross through these networks to sublayers or even to substrate, and react with Si bond layer, producing severe oxidization and degradation of EBC. Over the past years, researchers have studied the accelerated oxidation of $\mathrm{SiC}$ in detail when exposed to high-temperature steam and found that the oxidation occurred at a parabolic rate while volatilization by a linear rate [23]. With the protection of EBCs, the life of SiC components was improved at least 3 times based on engine testing [24]. Nevertheless, for higher operating temperature, the oxidation and corrosion rates are further accelerated, especially with the presenting of open penetration channels for steam and corrosives in the coating. Therefore, to obtain long operating life, a completely dense film without open-pores is of paramount importance.

Considerable efforts have been put into developing dense EBCs mainly from two aspects. One is concerning the suitable deposition techniques and the optimization of deposition parameters. A lot of studies have tried various preparing techniques, such as sol-gel [25], slurry [26-28], chemical vapor deposition (CVD) [29], and thermal spray techniques including air plasma spray (APS) [6, 30-32], electron-beam physical vapor deposition (EB-PVD) [33], plasma spray physical vapor deposition (PS-PVD) [34-37], and so on. Among them, the thermal spray technique is primarily selected for its high deposition temperature, which can completely melt the powder materials and form a dense coating. Modification of deposition parameters reduced the loss of $\mathrm{Si}$ and phase decomposition during the powder spraying [38, 39], as well as conductive to evaporate the species with high vapor pressure and form the stoichiometric coatings [18]. Increasing the substrate temperature facilitates the crystallization of each layer $[2,31,40]$. The other one is the post densify treatment of porous EBC. Several researchers tried to eliminate vertical cracks by the post-annealing treatment $[32,40,41]$. However, due to the significant CTE mismatch of YbMS and SiC substrate, mud cracks with a wide average spacing 
were presented and vertically penetrated both the top and middle layers [18]. Our group covered the surface of EBCs with an aluminum layer of several microns and then reacted in situ to form a dense alumina layer of several hundred nanometers, which effectively improved the corrosion resistance of coatings [42]. Nevertheless, the dense film is too thin to protect coating for a long time, and it is easily damaged by foreign objects in the engine environment.

This work proposed a densification method that blocked these open pores in the coating through pressure infiltration of molten aluminum. Tri-layer EBC of YbMS/mullite/Si system and aluminum film were firstly produced by PS-PVD and magnetron sputtering techniques, respectively. Then the infiltration process was mainly investigated, especially the influence of gas pressure and intrinsic pore structure on the infiltration behavior. Four different pressure conditions were carried out, including spontaneous and pressure assistant infiltration. Results showed that the infiltration results were determined by both the pressure condition and the pore geometry. According to the actual pore geometries, a zigzag pore model with multiple converging and diverging segments was established [21], and there is a mathematical relationship between the known geometry and the critical infiltration pressure. Once the critical pressure is exceeded, the infiltration will occur successfully. Experimental results also confirmed this mathematic relationship, which indicated that for a given system, the deep infiltration of the melt can be achieved just by adjusting the gas pressures, thus forming a thick dense film.

\section{Experimental procedures}

\subsection{Coating preparation}

Tri-layer system EBCs, comprised of top layer $\mathrm{Yb}_{2} \mathrm{SiO}_{5}$, middle layer mullite $\left(3 \mathrm{Al}_{2} \mathrm{O}_{3}\right.$ $2 \mathrm{SiO}_{2}$ ), and bond layer $\mathrm{Si}$, were deposited on $\mathrm{SiC}_{\mathrm{f}} / \mathrm{SiC}$ substrates, using PS-PVD facility (Sulzer-Metco Multicoat) assembled an $\mathrm{O} 3 \mathrm{CP}$ gun. The detailed deposition parameters are listed in Table 1. The thickness of each layer of $\mathrm{Yb}_{2} \mathrm{SiO}_{5}$, mullite, and $\mathrm{Si}$ is about $100 \mu \mathrm{m}, 50$ $\mu \mathrm{m}$, and $50 \mu \mathrm{m}$, respectively. Afterward, the EBC coated CMC substrate was placed in a magnetron sputtering facility (J-1250, Jingzhou Industrial Coating, China) to deposit a metal aluminum film of about $5 \mu \mathrm{m}$ onto the surface of EBCs. Pure Al target (99.99\%) was used for the deposition, as well as the deposition parameters with a direct current of $3 \mathrm{~A}$, a voltage of 
$150 \mathrm{~V}$, and a vacuum of $5 \times 10^{-3} \mathrm{~Pa}$.

\subsection{Infiltration process}

Before the vacuum infiltration, the Al-coated samples were sealed in a quartz tube with a vacuum low to $10^{-3} \mathrm{~Pa}$. The film was heat-treated for $2 \mathrm{~h}$ in a high-temperature furnace at $750{ }^{\circ} \mathrm{C}$ that was slightly higher than the melting point of aluminum (around $660{ }^{\circ} \mathrm{C}$ ) to fully melt and infiltrate the metal aluminum.

The pressure assistant infiltration was carried out using a two-step method. Firstly, the film was heated to $750{ }^{\circ} \mathrm{C}$ at a rate of $4{ }^{\circ} \mathrm{C} / \mathrm{min}$ in a vacuum furnace to fully melt the metal aluminum. The second step is to backfill a certain pressure $(2 \mathrm{kPa}, 20 \mathrm{kPa}, 100 \mathrm{kPa}$, respectively) of ultrahigh purity argon $\left(\mathrm{Ar} \geqslant 99.999 \%, \mathrm{O}_{2}<0.001 \mathrm{ppm}\right)$ into the furnace and hold for $1 \mathrm{~h}$ to obtain a stable infiltration depth.

\subsection{Microstructural characterization}

The surface of coatings and polished cross-section was characterized using Scanning Electron Microscope (SEM, SU6600, Hitachi, Japan) by secondary electrons. Elements maps were identified by energy-dispersive X-ray spectroscopy (EDS).

\section{Results}

\subsection{Microstructure of coating system before melt infiltration}

Before infiltration, an aluminum film was first prepared on the surface of the as-sprayed EBC. Fig. 1 shows the microstructure of the multiple-layer coating system before and after magnetron sputtering aluminum films. Obvious micro-cracks appear on the surface of assprayed tri-layer EBC in Fig. 1a, which is generated due to the rapid cooling of molten particles in the PS-PVD facility. These cracks are harmful for internal coatings because they supply infiltration channels for corrosives like water vapor, oxygen, molten salts. Fig. $1 \mathrm{~b}$ indicates a crack-free surface after the overlaying of aluminum film. The cross-section morphology of the hybrid coating is exhibited in Fig.1c. A dense film composed of closely arranged columns with a thickness of about $5 \mu \mathrm{m}$ covers evenly on the top coating. It should be noted that this film also blocks the entrance of EBCs openings, which explains the difference between the two surface morphologies. The elemental mapping confirms that the dense layer is aluminum. Thus, the porous tri-layer EBC surface, especially the exposed open pores, was completely covered by 
the additional dense aluminum film.

\subsection{Vacuum spontaneous infiltration results of aluminum into open pores}

The vacuum infiltration is generally considered as one of the conditions for spontaneous infiltration, and the results are shown in Fig. 2. The polished cross-section of the coating, as seen in Fig.2a, indicated that the top film was still stopped at the pore entrance and almost no infiltration. Elemental maps around the pore entrance, marked with a blue rectangle, were shown in Fig.2b-d. The aluminum distribution also confirmed its non-infiltration. The external and internal of the pores are both vacuum during infiltration. Consequently, there are no external gas to pressure the melt infiltration, and no internal gas to hinder its infiltration. Infiltration is

mainly driven by the surface tension of melt in capillary channels. Because of the poor wettability of melt on EBC materials, the driving force is too small to press melt into the pores. Besides, the complex pores or networks maybe one of the powerful retarding factors of infiltration. Therefore, it is difficult to compel molten aluminum into the actual pores of coatings under the vacuum condition only driven by the melt surface tension.

\subsection{Low-pressure infiltration results of aluminum into open pores}

A protective atmosphere with a low pressure of $2 \mathrm{kPa}$ was introduced onto the melt after vacuuming inside the pores, and the infiltration results were shown in Fig.3. Fig.3a-c displayed different infiltration depths of molten aluminum under the same pressure condition. A small amount of melt filled up near the pore entrance. The composition analysis of points I and II exhibited the existence of aluminum, which confirmed the aluminum infiltration and further oxidized to form alumina. In this case, infiltration driving force contains not only the surface tension of melt but also the external gas pressure, which leads to larger driving forces and a deeper depth compared with that under vacuum conditions. It should be noted that the pore morphologies were diverse and extremely irregular, including size and shape, so the result of each pore was slightly different, but there was obvious infiltration. Consequently, the external gas is beneficial for pushing the melt to infiltrate, however, the depth is shallow as a result of the low assistant pressure.

To confirm the influence of external gas pressure on the infiltration depth, the external pressure was further increased to $20 \mathrm{kPa}$, as well as the same vacuum inside, and the infiltration results are shown in Fig.4. Interestingly, despite driving by the same pressure, completely 
different infiltration results were obtained in each channel pore that ceased at different positions. We listed three typical depths here, reached at the top layer (Fig.4a), middle layer (Fig.4b), and bottom layer (Fig.4c), respectively. This work further investigated another seven pores, and the statistical results of the infiltration depths were shown in Fig.4d. It can be seen that higher external gas pressure increased the infiltration depth significantly. The external and internal conditions of these pores are identical, but their intrinsic geometric characteristics are significantly different. As seen in each cross-section image of the pore, there existed large geometric mutations, including expansion or contraction. This may be one of the main reasons for the extensive distribution range of infiltration depths, which is similar to that in Fig.3. Therefore, higher external gas pressure generally increased the infiltration depth significantly, but for some special pores, this increase failed, and the reason for this phenomenon will be discussed in detail below.

\subsection{High-pressure infiltration results of aluminum into open pores}

To weaken the influence of the special pore, a high assistant pressure of $100 \mathrm{kPa}$, which is close to atmospheric pressure and easy to achieve, was exerted onto the melts. The infiltration results in two different channel pores are shown in Fig. 5, one is a regular pore with relatively parallel walls, another one is an irregular pore with series converging and diverging geometries, and the expansion angles of the pore wall are equivalent to that in Fig.4. With the assistant of this high pressure, the melt fully filled each pore no doubtfully. The result was completely different from the condition of $20 \mathrm{kPa}$, indicating that the surface tension induced by capillary pores no longer dominated, but was replaced by external pressure. Therefore, driven by the high external assistant pressure, the melt successfully moves across the structural barriers and reaches the bottom of pores.

\section{Discussions}

\subsection{Determine factors of infiltration depth in pores}

According to the infiltration results under four different conditions, the factors that determine the infiltration depth must include the external pressure, as well as the pore geometry [43-45]. To figure out how these parameters work, a mathematical model needs to be established. First of all, considering the irregular outline of these pores in actual environmental barrier coatings $[18,21,22]$, the work established a wrinkle geometry that contains series 
converging and diverging segments, as shown in Fig. 6a. Denote the pore length by $H$, the pore radius by $r$, and the pore wall inclining angle by $\alpha$. Define the inclining angle $\alpha$ to be positive $(\alpha>0)$ in converging segments and negative $(\alpha<0)$ in diverging segments. For a given structure, their geometric relationship between the pore outline and the depth is known, assuming the functional relationships are $r=S_{\mathrm{r}}(h)$ and $\alpha=S_{\alpha}(h)$.

Based on the geometry model, the work selected an infiltration unit to analyze the pressures of the melt and obtain the infiltration physical model, as seen in Fig. 6b. For the poor wettability of molten aluminum on EBC materials, the direction of the curvature of the melt surface in diverging segment is opposite to the melt movement [43], which also has been explained in previous research [21]. Denote the infiltration depth by $h$ and taking the curved liquid surface in the diverging segment as the research object. There are mainly four kinds of pressures, which have been marked in Fig. 6b: (1) $P_{\text {ext: }}$ external gas pressure, whose direction is consistent with that of melt movement; 2) $P_{\text {cap }}$ : capillary pressure, i.e., additional pressure below the bending liquid surface, whose direction is identical with the curvature center of the bending liquid surface; 3) $P_{\text {int: }}$ internal gas pressure induced by the entrapped gas, whose direction is opposite with that of melt movement; 4) $P_{\mathrm{m}}$ : mass pressure, namely gravity here. It should be emphasized that gravity in lateral pores was offset by the rigid pore walls, so this research mainly focuses on vertical channel pore for its complexity in the physical force analysis of melt during infiltration. The branches of the channel pore can be considered as a combination of vertical and lateral pores, and the intersections can be regarded as a huge expansion and contraction.

Assume that:

(1) Ignore the chemical reaction between molten aluminum and coating materials, so the pores are of an invariantly stable shape;

(2) View the molten aluminum as continuum, homogeneous, and an incompressible Newtonian fluid;

(3) Treat the flow of melt as a thermodynamic equilibrium.

As indicated by the experimental results, the maximum infiltration depth $(h)$ depends on wetting properties of melt, intrinsic characteristics of pores, applied external pressure, and internal pressure, which can be described by the function that 


$$
h=f\left(\theta, S, P_{\mathrm{ext}}, P_{0}\right)
$$

where $\theta$ represents the contact angle of molten aluminum on the pore wall, which characterize the wettability of melt; $S$ represents the functions of the geometrical parameters of pores, including pore wall inclining angle $\alpha$ and pore radius $r ; P_{0}$ represents the initial gas pressure induced by the gas trapped in pores by the melt before the infiltrating process.

The driving pressure during infiltrating process is expressed as follows:

$$
P=\frac{2 \sigma \cos \left[\theta-S_{\alpha}(h)\right]}{S_{\mathrm{r}}(h)}+P_{\mathrm{ext}}-P_{0} \frac{\int_{0}^{H} S_{\mathrm{r}}^{2}\left(h_{3}\right) \mathrm{d} h_{3}}{\int_{h}^{H} S_{\mathrm{r}}^{2}\left(h_{2}\right) \mathrm{d} h_{2}}+\mathrm{f} \rho h
$$

where the first term represents the capillary pressure; the second and the third terms represent the external gas pressure and the internal gas pressure, respectively; the fourth term represents the mass pressure, which is gravity in this study.

After a long enough infiltrating process, the melt ceased and the infiltration depth reached a maximum value $\left(h_{\max }\right)$, which means that the system has reached an equilibrium state. Thus, the driving pressure at the melt surface is zero, so we have the equation that

$$
\frac{2 \sigma \cos \left[\theta-S_{\alpha}\left(h_{\max }\right)\right]}{S_{\mathrm{r}}\left(h_{\max }\right)}+P_{\mathrm{ext}}-P_{0} \frac{\int_{0}^{H} S_{\mathrm{r}}^{2}\left(h_{3}\right) \mathrm{d} h_{3}}{\int_{h_{\max }}^{H} S_{\mathrm{r}}^{2}\left(h_{2}\right) \mathrm{d} h_{2}}+\mathrm{f} \rho h_{\text {max }}=0
$$

Among them, the mass pressure (here expressed as gravity) is so small that can be ignored. Without considering the mass pressure, the mathematic model of vertical pore infiltration is equivalent to that of lateral pore infiltration. Then the expression can be simplified as:

$$
\frac{2 \sigma \cos \left[\theta-S_{\alpha}\left(h_{\max }\right)\right]}{S_{\mathrm{r}}\left(h_{\max }\right)}+P_{\text {ext }}-P_{0} \frac{\int_{0}^{H} S_{\mathrm{r}}^{2}\left(h_{3}\right) \mathrm{d} h_{3}}{\int_{h_{\max }}^{H} S_{\mathrm{r}}^{2}\left(h_{2}\right) \mathrm{d} h_{2}}=0
$$

There are four types of variables in the equation, namely, melt wettability, pores geometric parameters, external pressure, and internal pressure. Due to the phase decomposition of coating materials in extremely heated plasma flame during deposition, the phase composition of the pore wall is non-uniform [26, 29]. Therefore, even in the same pore, the melt wettability on the pore wall is not a constant. According to literature, aluminum poorly wets EBC materials, with a contact angle of slightly less than $90^{\circ}$. In practice, it is difficult to design good wettability of 
melt on the surface of multiple materials at the same time. To facilitate the calculation and analysis, this research fixed the aluminum contact angle at $80^{\circ}$, focusing on the interaction of gas pressure and geometrical characteristics on the infiltration results.

\subsection{Influence of gas pressure on infiltration depth}

To reach a certain infiltration depth $h$ for a pore with a known geometry, there must be a critical pressure $\left(P_{\text {t-ext }}\right)$ to overcome all of the obstacle pressures. Gas pressures serve as the significant factors affecting the maximum infiltration depth. The external gas pressure drives the infiltration. Raising external pressure may increase infiltration depth theoretically. According to equation (4), the expression of the critical pressure can be written as:

$$
P_{\mathrm{t} \text {-ext, } P_{0}}=-\frac{2 \sigma \cos \left[\theta-S_{\alpha}(h)\right]}{S_{\mathrm{r}}(h)}+P_{0} \frac{\int_{0}^{H} S_{\mathrm{r}}^{2}\left(h_{3}\right) \mathrm{d} h_{3}}{\int_{h}^{H} S_{\mathrm{r}}^{2}\left(h_{2}\right) \mathrm{d} h_{2}}
$$

When the internal pressure minimized to vacuum, that is, the initial internal pressure $P_{0}=0$, the critical expression can be greatly simplified as follow:

$$
P_{\mathrm{t} \text { ext, vacuum }}=-\frac{2 \sigma \cos \left[\theta-S_{\alpha}(h)\right]}{S_{\mathrm{r}}(h)}
$$

For a better understanding of the relationship between the critical pressure, the pore geometries, and the internal pressure, specific values were assigned according to the actual range of each parameter. Among them, the entrance radius is $R_{0}=2 \mu \mathrm{m}$, the pore depth is $H=$ $20 \mu \mathrm{m}$, and the inclining angle of pore wall is $\alpha= \pm 10^{\circ}$ (the converging segment is $10^{\circ}$ and the diverging segment is $-10^{\circ}$ ). Thus, two curves of $P_{\mathrm{t} \text {-ext, } P 0}$ and $P_{\mathrm{t} \text {-ext, vacuum }}$ can be obtained by integrating equation (5) and (6), respectively, as shown in Fig. 7. The blue line demonstrates the critical pressure $P_{\mathrm{t}-\mathrm{ext}}, 100 \mathrm{kPa}$ with the initial pressure to be $100 \mathrm{kPa}$, which is close to atmospheric pressure. The green line indicates the internal pressure evolution along with the melt infiltration. The pink line reflects the critical pressure $P_{\mathrm{t} \text {-ext, vacuum }}$ under the condition of internal vacuum initially. It should be noted that a negative critical pressure means that the melt resultant pressure is positive, in other words, the melt can infiltrate spontaneously without extra assistant. Since the internal pressure that hinders infiltration increases exponentially, an excessively large critical external pressure is required to obtain deep infiltration. There is no significant obstructiveness under the internal vacuum condition, so the critical pressure drops. 
Larger external gas pressure helps infiltration for both vacuum and non-vacuum conditions. The external pressure of $100 \mathrm{kPa}$ exceeds the majority of critical pressures during vacuum infiltration to arrive at a deeper depth based on the established pore model.

To verify the influence of external pressures on infiltration depths in practice, this work selected ten vertical pores under each external pressure condition randomly and obtained the statistical results shown in Fig. 8. Under vacuum conditions, that is, the external gas pressure is 0 , almost all pores are not obviously infiltrated, which is consistent with Fig. 2. This indicates the poor wettability of molten aluminum on the surface of top materials $\mathrm{Yb}_{2} \mathrm{SiO}_{5}$. Raising the external pressure to $2 \mathrm{kPa}$ improved the infiltration depth to about $10 \%$. Further increasing the pressure to $20 \mathrm{kPa}$ improved the average depth to more than $50 \%$. It is worth noting that the depth was widely distributed, and the individual results were similar to that of $2 \mathrm{kPa}$, while individual pores were full filled. Infiltrating with a high pressure of $100 \mathrm{kPa}$, which is easy to implement because it is close to atmospheric pressure, melt successfully filled these ten pores, Partial results are shown in Fig. 5 above. Therefore, the pressure of $100 \mathrm{kPa}$ has exceeded the maximum critical pressure determined by these zigzag structures.

\subsection{Influence of pore geometry on infiltration depth}

The formation mechanism of irregular pore geometry, including random width and zigzag outline, as shown in the cross-section images of pores in Part 3, is related to the release of stress during the deposition and cooling process of coatings $[10,14,30]$. The material powder is melted into droplets in the high-temperature plasma flame. Then they impact the cold substrate under the high-speed flame and cooling down rapidly to form splats. A large quenching stress, which can reach as high as several GPa [46], is generated in the coating during the rapid cooling stress, which further induced vertical pores or microcracks. These pores in individual splat are independent and are successively stacked to form coatings. They intersected with each other to form a complex configuration. As shown in the schematic diagram of Fig.9, the final pore or crack is always considered to be a zigzag morphology. For pattern I, although there is no lateral delamination, the melt still encounters several diverging structures when flowing in the pore at the intersections. Moreover, lateral delamination usually exists in the pores and is shown as pattern II, which significantly enlarged the diverging structure concluding the length, width, and opening angles. 
For other random pores with unknown geometry, the expression of critical pressure also can be expressed as follows [47].

$$
P_{\text {text, vaccum }}=-\frac{2 \sigma \cos (\theta-a)}{r}
$$

The relationship of critical pressure with the geometric parameters including pore wall inclinations and pore radius during infiltrating is shown in Fig.10a. The four external assistant pressures of $0,2 \mathrm{kPa}, 20 \mathrm{kPa}$, and $100 \mathrm{kPa}$ are drawn as isobars on the $3 \mathrm{D}$ surface and also bottom project image by black, orange, blue, and pink curve respectively. The negative pressure value in the $3 \mathrm{D}$ surface means that the infiltration does not require external assistance. A positive inclining angle representing the converging structure results in a negative critical pressure. It means that in a tapered segment, no matter how wide the channel is, melt can infiltrate spontaneously without the assistant of external pressure. In contrast, a negative inclining angle corresponding to the diverging geometry results in a positive pressure value. The larger the diverging angle and the smaller the radius, the greater the critical value. In other words, the wider the pores, the more sensitive to expansion. Therefore, the diverging segment of the zigzag structure hinders the melt infiltration, so external pressure should be applied to push the melt. The minimum value of the hindrance angle depends on the wettability of melt, which is consistent with literature reports. The pores geometric parameters can be divided into five areas according to the four assistant pressures in the infiltrating experiment, as seen in Fig.10b, as well as the project view in Fig.10a. The area on the right of each curve indicates the geometries that can be successfully infiltrated under the corresponding pressure, and the area on the left represents the failure of the pressure.

To prove the proposed relationship between the external pressure and the pore geometric parameters, the local enlarged views of four infiltrated pores under the three pressure conditions were listed in Fig.11. The four geometric parameters ahead of the terminal liquid surface, including the radius and the inclination angles, were measured and marked in Fig.11(a) (d), respectively. Each actual pore parameter was divided into corresponding regions according to Fig.10b. The parameters in Fig.11a-c were all located in area IV, which was on the left of the isobar of $20 \mathrm{kPa}$, indicating that this pressure is not high enough to push the melt. The failed infiltration results when encounter these structures in Fig.11a-c has confirmed this conclusion. 
Similarly, the parameters in Fig.11d were also located in area IV, but on the right of its assistant pressure of $100 \mathrm{kPa}$, indicating that the pressure was high enough to push the infiltration in these pores. It should be noted that all of these parameters were on the right of the isobar of 100 $\mathrm{kPa}$, so melt infiltrated into similar pores successfully under this condition, which was confirmed by former results in Fig.5 and Fig.8. Therefore, raising the assistant pressure over the critical value can overcome the resistance caused by pore geometries and achieve deep infiltration.

Deep infiltration of the porous coating was achieved by adjusting the external and internal gas pressure in practice. The experimental steps and mechanism can be described in the schematic diagram of Fig. 12. First, a dense aluminum film was prepared on the surface of EBC to close the openings. Atmospheric gas was entrapped in the pores by the dense film. Then the sample was placed in a high-temperature furnace combined with a vacuum pump. The sample was heated up to exceed the melting point of aluminum and pumped to a high vacuum. At the same time, the air inside the pore was pumped out through the melt, and there was no pressure difference between the external and internal of the pore. The initial internal pressure before infiltration was close to 0 . Infiltrations occurring in the first two steps are both known as spontaneous infiltration. Finally, a certain pressure of almost oxygen-free argon was backfilled into the high-temperature furnace, which is equivalent to applying external pressure on the melt to drive infiltration. A significant difference of pressure herein was achieved. External assistant pressure was determined by the pore geometries including radius and inclination. This means that under a certain external gas pressure, the geometric structure determines the infiltration depth.

In this way, the theoretical vacuum inside and pressure outside can be realized in practice, and the different infiltration depths can be obtained by controlling the external assistant pressures although the determinant of pore geometric structures.

\section{Conclusions}

To improve the corrosion resistance of EBCs, this research is devoted to achieve thick dense film by filling open-pores in coating with molten aluminum. This work conducted a series of infiltration experiments under four different pressure conditions, and then established a mathematic relationship between assistant pressure and pores intrinsic geometry according to 
the wrinkle pore geometry model. The detailed conclusions are as follows.

(1) Molten aluminum was difficult to spontaneously infiltrate in pores of EBCs without external assistant.

(2) Melt infiltration occurred successfully with the assistance of external gas pressures. Distinct terminal depths were appeared under different pressure conditions, even the same pressure condition, which is related to pores intrinsic geometries.

(3) The critical assistant pressure to reach each depth mainly depended on pores geometry and internal gas pressure. Under the internal vacuum condition, the critical pressure increases with the increase of the diverging angle and the decrease of the pore radius.

(4) Infiltration results were in good agreement with the established mathematic model of infiltration. Deep infiltration was successfully achieved by raising external pressure above the critical value and making a vacuum inside pores simultaneously, thus obtaining thick dense film.

\section{Acknowledgments}

This project was supported by the National Natural Science Foundation of China (Grant No. 51901175), the Guangdong Province Outstanding Youth Foundation (2021B1515020038), the Guangzhou Technical Research Program (201906010015), the Industry-University-Research project funded by the Aero Engine Corporation of China (No. HFZL2019CXY015), the Postdoctoral Research Foundation of China (No. 2020T130499, No. 2019M653602), and the National Program for Support of Top-notch Young Professionals.

\section{References}

[1] Padture NP. Advanced structural ceramics in aerospace propulsion. Nat Mater 2016, 15: 804-809.

[2] Richards BT, Wadley HNG. Plasma spray deposition of tri-layer environmental barrier coatings. $J$ Eur Ceram Soc 2014, 34: 3069-3083.

[3] Turcer LR, Padture NP. Rare-earth pyrosilicate solid-solution environmental-barrier coating ceramics for resistance against attack by molten calcia-magnesia-aluminosilicate (CMAS) glass. J Mater Res 2020, 35: 2373-2384.

[4] Padture NP. Environmental degradation of high-temperature protective coatings for ceramic-matrix composites in gas-turbine engines. npj Materials Degradation 2019, 3.

[5] Sullivan RM. On the oxidation of the silicon bond coat in environmental barrier coatings. $J$ Eur Ceram Soc 2021, 41: 557-562. 
[6] Wang $\mathrm{Y}$, Niu $\mathrm{Y}$, Zhong $\mathrm{X}$, et al. Water vapor corrosion behaviors of plasma sprayed $\mathrm{RE}_{2} \mathrm{SiO}_{5}(\mathrm{RE}=\mathrm{Gd}$, Y, Er) coatings. Corros Sci 2020, 167: 108529.

[7] Sun Y, Xiang H, Dai FZ, et al., Preparation and properties of CMAS resistant bixbyite structured highentropy oxides $\mathrm{RE}_{2} \mathrm{O}_{3}(\mathrm{RE}=\mathrm{Sm}, \mathrm{Eu}, \mathrm{Er}, \mathrm{Lu}, \mathrm{Y}$, and $\mathrm{Yb})$ : Promising environmental barrier coating materials for $\mathrm{Al}_{2} \mathrm{O}_{3} / / \mathrm{Al}_{2} \mathrm{O}_{3}$ composites. $J$ Adv Ceram 2021, 10 .

[8] Bakan E, Kindelmann M, Kunz W, et al. High-velocity water vapor corrosion of Yb-silicate: Sprayed vs. sintered body. Scripta Mater 2020, 178, 468-471.

[9] Zhang WW, Li GR, Zhang Q, et al. Comprehensive damage evaluation of localized spallation of thermal barrier coatings. J. Adv. Ceram 2017, 6: 230-239.

[10] Zhang B, Song W, Wei L, et al. Novel thermal barrier coatings repel and resist molten silicate deposits. Scripta Mater 2019, 163: 71-76.

[11] Ma Q, Cai L. Fabrication and oxidation resistance of mullite/yttrium silicate multilayer coatings on C/SiC composites. J Adv Ceram 2017, 6: 360-367.

[12] Lee KN. Special Issue: Environmental Barrier Coatings. Coatings 2020, 10.

[13] Lee KN. $\mathrm{Yb}_{2} \mathrm{Si}_{2} \mathrm{O}_{7}$ Environmental barrier coatings with reduced bond coat oxidation rates via chemical modifications for long life. J Am Ceram Soc 2019, 102: 1507-1521.

[14] Xu Y, Hu X, Xu F, et al. Rare earth silicate environmental barrier coatings: Present status and prospective. In Ceram Int 2017, 43: 5847-5855.

[15] Guo L, Li G, Gan Z. Effects of surface roughness on CMAS corrosion behavior for thermal barrier coating applications. $J$ Adv Ceram 2021, 10.

[16] Tian Z, Zhang J, Zhang T, et al. Towards thermal barrier coating application for rare earth silicates $\mathrm{RE}_{2} \mathrm{SiO}_{5}$ (RE= La, Nd, Sm, Eu, and Gd). J Eur Ceram Soc 2019, 39: 1463-1476.

[17] Tian Z, Zhang J, Zheng L, et al. General trend on the phase stability and corrosion resistance of rare earth monosilicates to molten calcium-magnesium-aluminosilicate at $1300{ }^{\circ}$ C. Corros Sci 2019, 148: 281292.

[18] Richards BT, Sehr S, Franqueville F, et al. Fracture mechanisms of ytterbium monosilicate environmental barrier coatings during cyclic thermal exposure. Acta Mater 2016, 103: 448-460.

[19] Jang BK, Feng FJ, Lee KS, et al. Thermal behavior and mechanical properties of $\mathrm{Y}_{2} \mathrm{SiO}_{5}$ environmental barrier coatings after isothermal heat treatment. Surf Coat Tech 2016, 308: 24-30.

[20] Al Nasiri N, Patra N, Jayaseelan DD, et al. Water vapour corrosion of rare earth monosilicates for environmental barrier coating application. Ceram Int 2017, 43: 7393-7400.

[21] Dong L, Liu M-J, Zhang X-F, et al. Infiltration thermodynamics in wrinkle-pores of thermal sprayed coatings. Appl Surf Sci 2020, 543: 148847.

[22] Chen L, Yang G-J. Epitaxial growth and cracking of highly tough 7YSZ splats by thermal spray technology. J Adv Ceram 2017, 7: 17-29.

[23] Robinson RC, Smialek JL. SiC recession caused by $\mathrm{SiO}_{2}$ scale volatility under combustion conditions: I, experimental results and empirical model. J Am Ceram Soc 1999, 82: 1817-1825.

[24] Harry E, Eaton GDL. Accelerated oxidation of SiC CMC's by water vapor and protection via environmental barrier coating approach. J Eur Ceram Soc 2002, 22: 2741-2747.

[25] Jayaseelan DD, Ueno S, Ohji T, et al. Sol-gel synthesis and coating of nanocrystalline $\mathrm{Lu}_{2} \mathrm{Si}_{2} \mathrm{O}_{7}$ on $\mathrm{Si}_{3} \mathrm{~N}_{4}$ substrate. Mater Chem Phys 2004, 84: 192-195.

[26] Dayi EN, Al Nasiri N. Diffusion study of rare-earth oxides into silica layer for environmental barrier coating applications. J Eur Ceram Soc 2019, 39: 4216-4222.

[27] Ramasamy S, Tewari SN, Lee KN, et al. Slurry based multilayer environmental barrier coatings for 
silicon carbide and silicon nitride ceramics-I. Processing. Surf Coat Tech 2010, 205: 258-265.

[28] Lee KN, Waters DL, Puleo BJ, et al. Development of oxide-based High temperature environmental barrier coatings for ceramic matrix composites via the slurry process. $J$ Eur Ceram Soc 2021, 41: 1639-1653. [29] Ito A, Sekiyama M, Hara T, et al. Self-oriented growth of $\beta-\mathrm{Yb}_{2} \mathrm{Si}_{2} \mathrm{O}_{7}$ and $\mathrm{X} 1 / \mathrm{X}_{2}-\mathrm{Yb}_{2} \mathrm{SiO}_{5}$ coatings using laser chemical vapor deposition. Ceram Int 2020, 46: 9548-9553.

[30] Richards BT, Young KA, de Francqueville F, et al. Response of ytterbium disilicate-silicon environmental barrier coatings to thermal cycling in water vapor. Acta Mater 2016, 106: 1-14.

[31] Stolzenburg F, Kenesei P, Almer J, et al. The influence of calcium-magnesium-aluminosilicate deposits on internal stresses in $\mathrm{Yb}_{2} \mathrm{Si}_{2} \mathrm{O}_{7}$ multilayer environmental barrier coatings. Acta Mater 2016, 105: 189-198.

[32] Bakan E, Marcano D, Zhou DP, et al. $\mathrm{Yb}_{2} \mathrm{Si}_{2} \mathrm{O}_{7}$ Environmental barrier coatings deposited by various thermal spray techniques: A preliminary comparative study. $J$ Therm Spray Techn 2017, 26: 1011-1024.

[33] Poerschke DL, Hass DD, Eustis S, et al. Stability and CMAS resistance of ytterbium-silicate/hafnate EBCs/TBC for SiC Composites. J Am Ceram Soc 2015, 98: 278-286.

[34] Zhang X, Song J, Deng Z, et al. Interface evolution of Si/Mullite/ $\mathrm{Yb}_{2} \mathrm{SiO}_{5}$ PS-PVD environmental barrier coatings under high temperature. J Eur Ceram Soc 2020, 40: 1478-1487.

[35] Zhang XF, Wang C, Ye RJ, et al. Mechanism of vertical crack formation in $\mathrm{Yb}_{2} \mathrm{SiO}_{5}$ coatings deposited via plasma spray-physical vapor deposition. Journal of Materiomics 2020, 6: 102-108.

[36] Li D, Jiang P, Gao R, et al. Experimental and numerical investigation on the thermal and mechanical behaviours of thermal barrier coatings exposed to CMAS corrosion. J Adv Ceram 2021, 10.

[37] Liu MJ, Zhang M, Zhang X F, et al. Transport and deposition behaviors of vapor coating materials in plasma spray-physical vapor deposition. Appl Surf Sci 2019, 486: 80-92.

[38] Richards BT, Zhao HB, Wadley HNG. Structure, composition, and defect control during plasma spray deposition of ytterbium silicate coatings. J Mater Sci 2015, 50: 7939-7957.

[39] Lee JK, Kim HG. YSZ atmospheric plasma coating method for improved high temperature corrosion and wear resistance. J Mech Sci Technol 2020, 34: 3629-3633.

[40] Garcia E, Lee H, Sampath S. Phase and microstructure evolution in plasma sprayed $\mathrm{Yb}_{2} \mathrm{Si}_{2} \mathrm{O}_{7}$ coatings. J Eur Ceram Soc 2019, 39: 1477-1486.

[41] Garcia E, Garces HF, Turcer LR, et al. Crystallization behavior of air-plasma-sprayed ytterbium-silicatebased environmental barrier coatings. J Eur Ceram Soc 2021.

[42] Zhang X, Deng Z, Li H, et al. $\mathrm{Al}_{2} \mathrm{O}_{3}$-modified PS-PVD 7YSZ thermal barrier coatings for advanced gas-turbine engines. npj Materials Degradation 2020, 4.

[43] Rabbani HS, Zhao B, Juanes R, et al. Pore geometry control of apparent wetting in porous media. Sci Rep 2018, 8: 15729.

[44] Hu LB, Savidge C, Rizzo DM, et al. Commonly used porous building materials: Geomorphic pore structure and fluid transport. J Mater Civ Eng 2013, 25: 1803-1812.

[45] Kim J, Shin JH, Sohn S, et al. Analysis of non-uniform flow distribution in parallel micro-channels. $J$ Mech Sci Technol 2019, 33: 3859-3864.

[46] Matejicek J, Sampath SJAM. In situ measurement of residual stresses and elastic moduli in thermal sprayed coatings: Part 1: apparatus and analysis. Acta Mater 2003, 51: 863-872.

[47] Asekomhe SO, Elliott JAW. The effect of interface deformation due to gravity on line tension measurement by the capillary rise in a conical tube. Colloid Surface A 2003, 220: 271-278. 


\section{Table captions}

Table 1 Deposition parameters of tri-layer system EBCs prepared by PS-PVD technology 


\section{Figure captions}

Fig. 1 Microstructure of multiple-layer coatings before and after magnetron sputtering aluminum film: (a) as-prayed surface of EBC; (b)(c) surface and cross-section microstructure after magnetron sputtering aluminum films, respectively; (d) element mapping of aluminum of Fig.1c.

Fig. 2 Uninfiltrated pores in EBC under vacuum infiltration (also known as spontaneous infiltration) of molten aluminum: (a) cross-section view of the pore; (b) - (d) Al, O, and Si element maps of the blue rectangle area in Fig.2a.

Fig. 3 Near-entrance infiltrated pores under pressure-assisted infiltration at 2kPa: (a)-(c) crosssection view of the infiltrated channel pores; (d) composition analysis of the point I and II in Fig.3a.

Fig. 4 Partially infiltrated pores under pressure-assisted infiltration at 20kPa: (a) infiltration stopped inside the top $\mathrm{Yb}_{2} \mathrm{SiO}_{5}$ layer; (b) infiltration stopped inside the middle mullite layer; (c) infiltration stopped inside the bottom Si layer; (d) statistical infiltration depths of ten randomly selected pores.

Fig. 5 Fully infiltrated pores under pressure-assisted infiltration at 100kPa: (a) regular pore with smooth and relatively parallel walls; (b) irregular pore with rough and zigzag walls.

Fig. 6 Infiltration model in zigzag channel pore: (a) geometry model of channel pore with series converging and diverging structures and (b) physical model of melt infiltration, including four pressures that external gas pressure $\left(P_{\text {ext }}\right)$, internal gas pressure $\left(P_{\text {int }}\right)$, capillary pressure $\left(P_{\text {cap }}\right)$ induced by the curved surface of melt in microscale channels, and mass pressure $\left(P_{\mathrm{m}}\right)$ here is gravity.

Fig. 7 Relationship between critical external pressures $\left(P_{\text {text }}\right)$ and infiltration depth $(H)$ under different initial internal pressures: the blue line represents the value of $100 \mathrm{kPa}$, which is based on equation (5); the pink line represents the value of 0 , corresponding to equation (6).

Fig. 8 Improved infiltration depths by increasing external pressures, which is statistically known from the infiltration results of selected 10 pores under each external pressure

Fig. 9 Schematic diagram of the formation of zigzag morphology with converging and diverging structures

Fig. 10 (a) Critical pressure $\left(P_{\text {t-ext }}\right)$ as a function of pore wall inclining angle $(\alpha)$ and pore radius 
(r), as well as four isobars of experimental pressures that $0,2,20$, and $100 \mathrm{kPa}$; (b) the corresponding projection of the four isobars in Fig.10a, which divide the geometric parameters into five areas.

Fig. 11 Infiltration interface of partially infiltrated pores at pressure of (a)-(c) $20 \mathrm{kPa}$ and fully infiltrated pore at pressure of (d) $100 \mathrm{kPa}$.

Fig. 12 Schematic diagram illustrates the steps of deep infiltration 


\section{Tables}

Table 1 Deposition parameters of tri-layer system EBCs prepared by PS-PVD technology

\begin{tabular}{cccccc}
\hline Materials & $\begin{array}{c}\text { Current } \\
(\mathrm{A})\end{array}$ & $\begin{array}{c}\text { Plasma gas } \\
(\mathrm{slpm})\end{array}$ & $\begin{array}{c}\text { Feed rate } \\
(\mathrm{g} / \mathrm{min})\end{array}$ & $\begin{array}{c}\text { Stand-off distance } \\
(\mathrm{mm})\end{array}$ & $\begin{array}{c}\text { Pre-heating } \\
\left({ }^{\circ} \mathrm{C}\right)\end{array}$ \\
\hline $\mathrm{Si}$ & 1650 & $\mathrm{Ar} / \mathrm{He}=110 / 6$ & 8.2 & 450 & $\sim 500$ \\
Mullite & 2600 & $\mathrm{Ar} / \mathrm{He}=70 / 50$ & 10 & 1000 & $\sim 1000$ \\
$\mathrm{Yb}_{2} \mathrm{SiO}_{5}$ & 2400 & $\mathrm{Ar} / \mathrm{He}=100 / 20$ & 20 & 1000 & $\sim 800$ \\
\hline
\end{tabular}




\section{Figures}
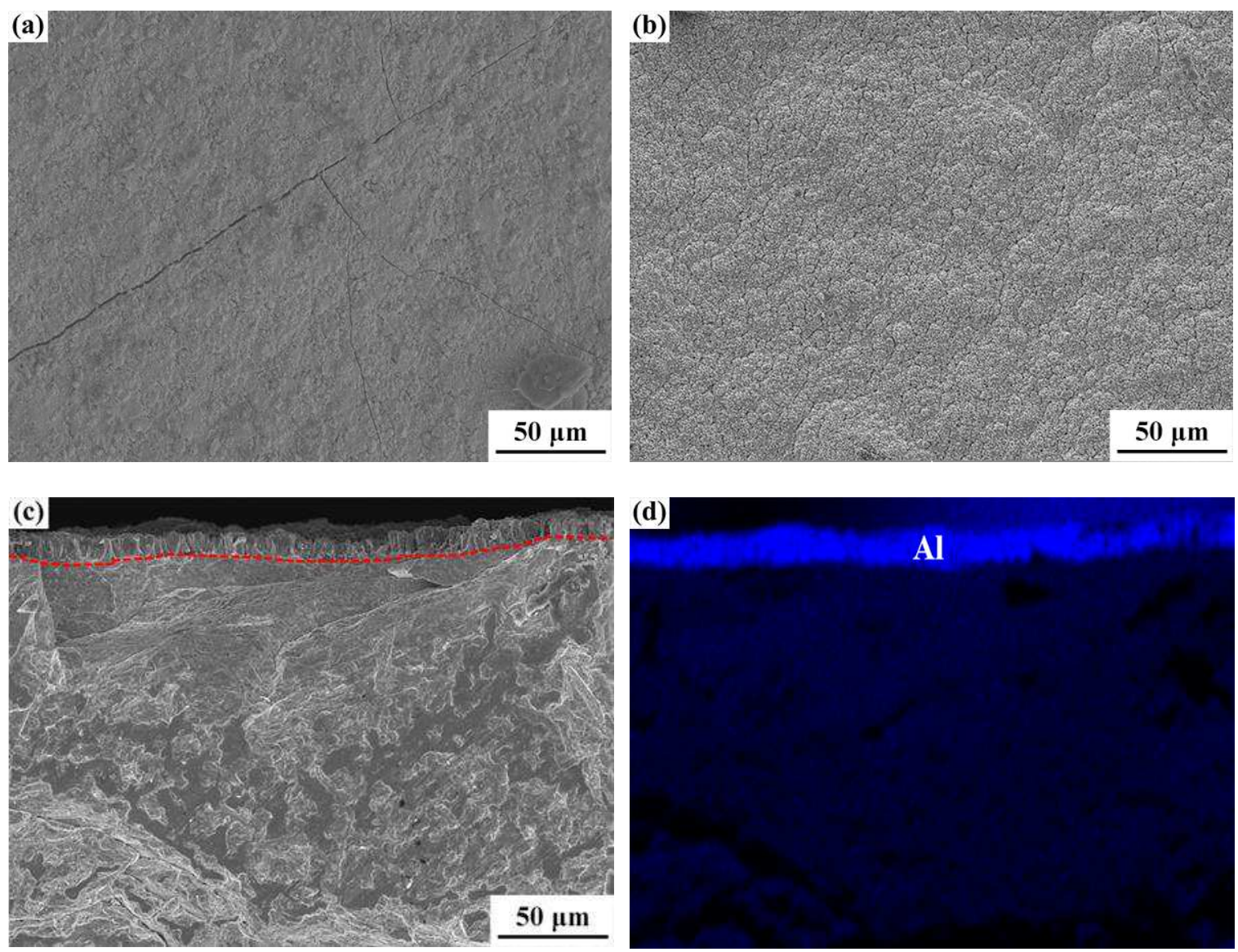

Fig. 1 Microstructure of multiple-layer coatings before and after magnetron sputtering aluminum film: (a) as-prayed surface of EBC; (b)(c) surface and cross-section microstructure after magnetron sputtering aluminum films, respectively; (d) element mapping of aluminum of Fig.1c.

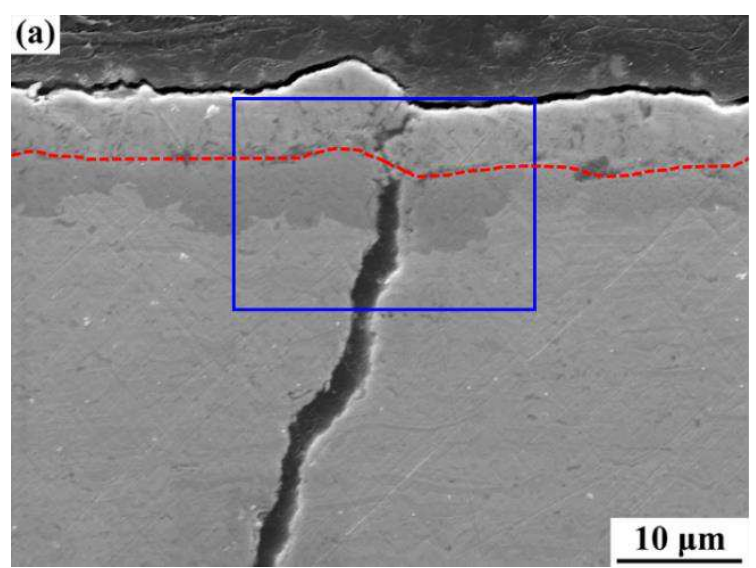



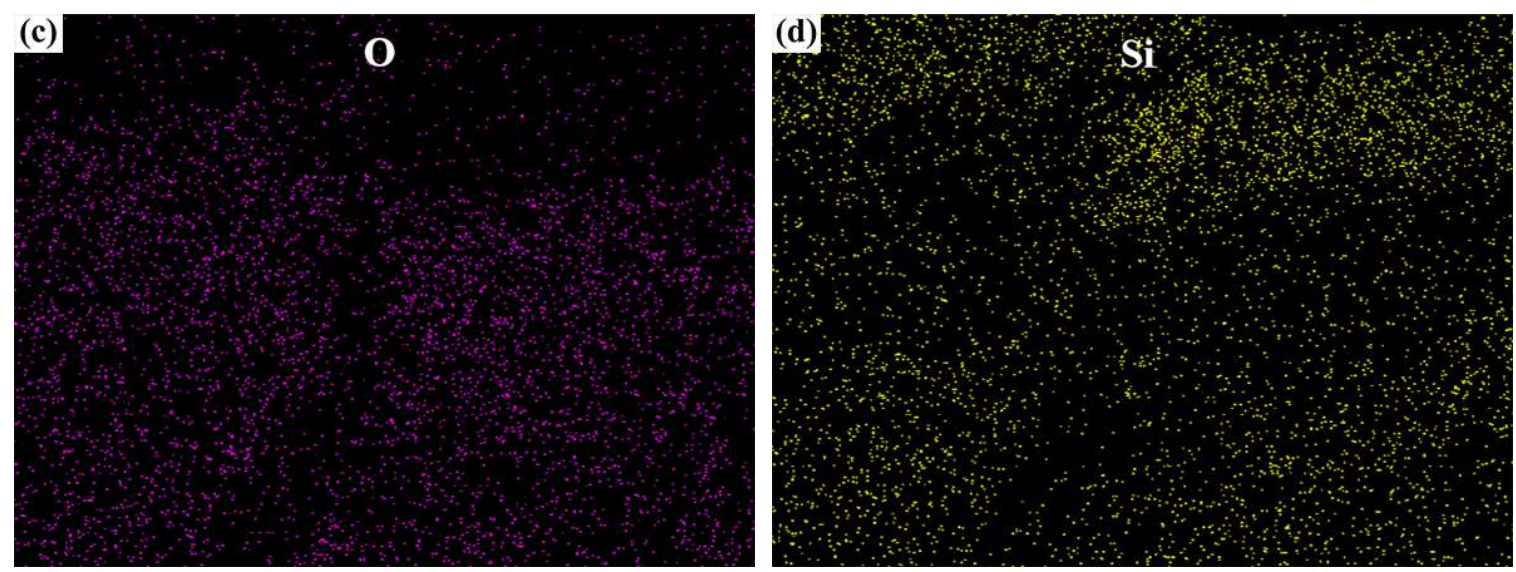

Fig. 2 Uninfiltrated pores in EBC under vacuum infiltration (also known as spontaneous infiltration) of molten aluminum: (a) cross-section view of the pore; (b) - (d) Al, O, and Si element maps of the blue rectangle area in Fig.2a.
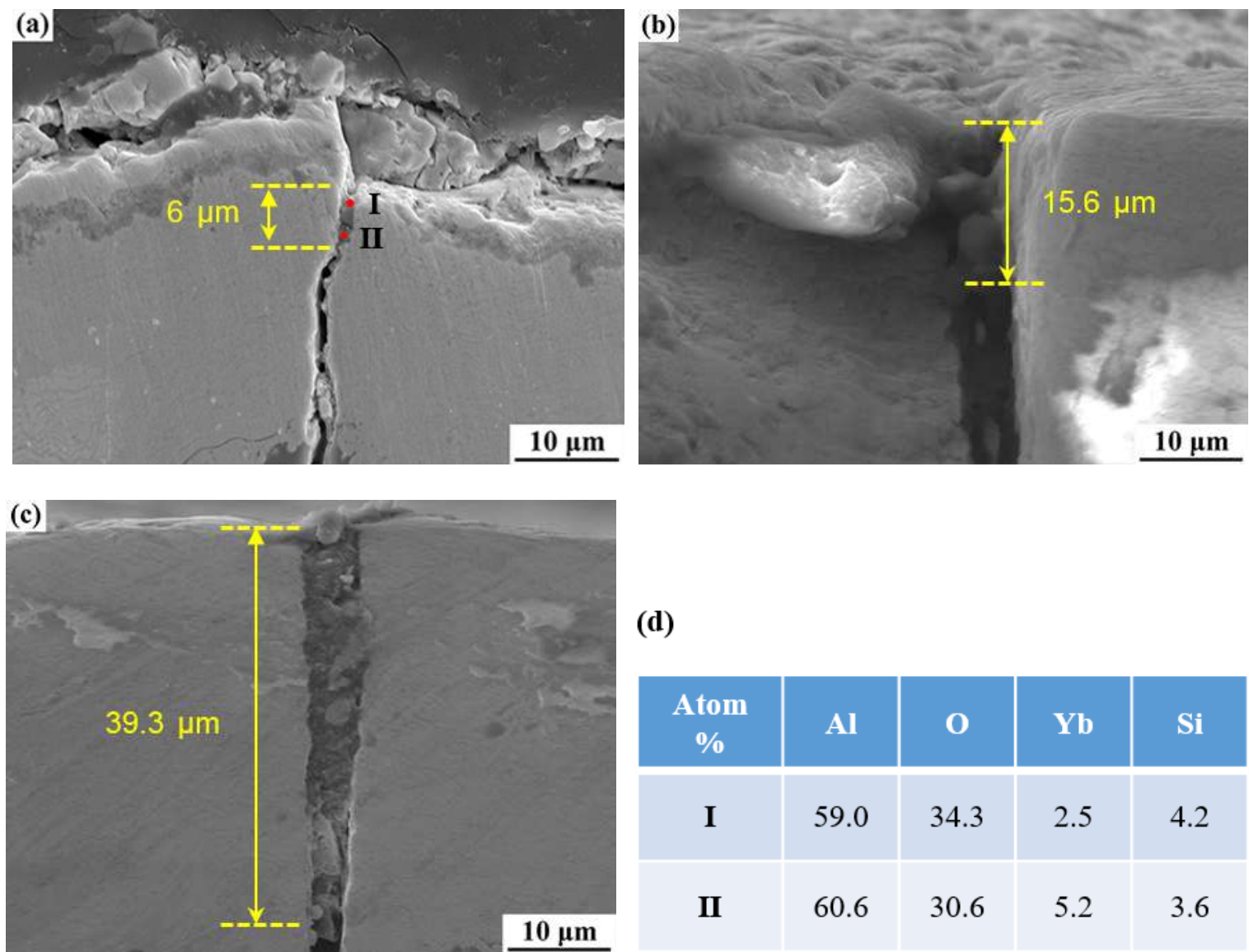

(d)

\begin{tabular}{|c|c|c|c|c|}
\hline $\begin{array}{c}\text { Atom } \\
\%\end{array}$ & Al & $\mathbf{0}$ & $\mathbf{Y b}$ & Si \\
\hline $\mathbf{I}$ & 59.0 & 34.3 & 2.5 & 4.2 \\
\hline II & 60.6 & 30.6 & 5.2 & 3.6 \\
\hline
\end{tabular}

Fig. 3 Near-entrance infiltrated pores under pressure-assisted infiltration at 2kPa: (a)-(c) cross-section view of the infiltrated channel pores; (d) composition analysis of the point I and II in Fig.3a. 

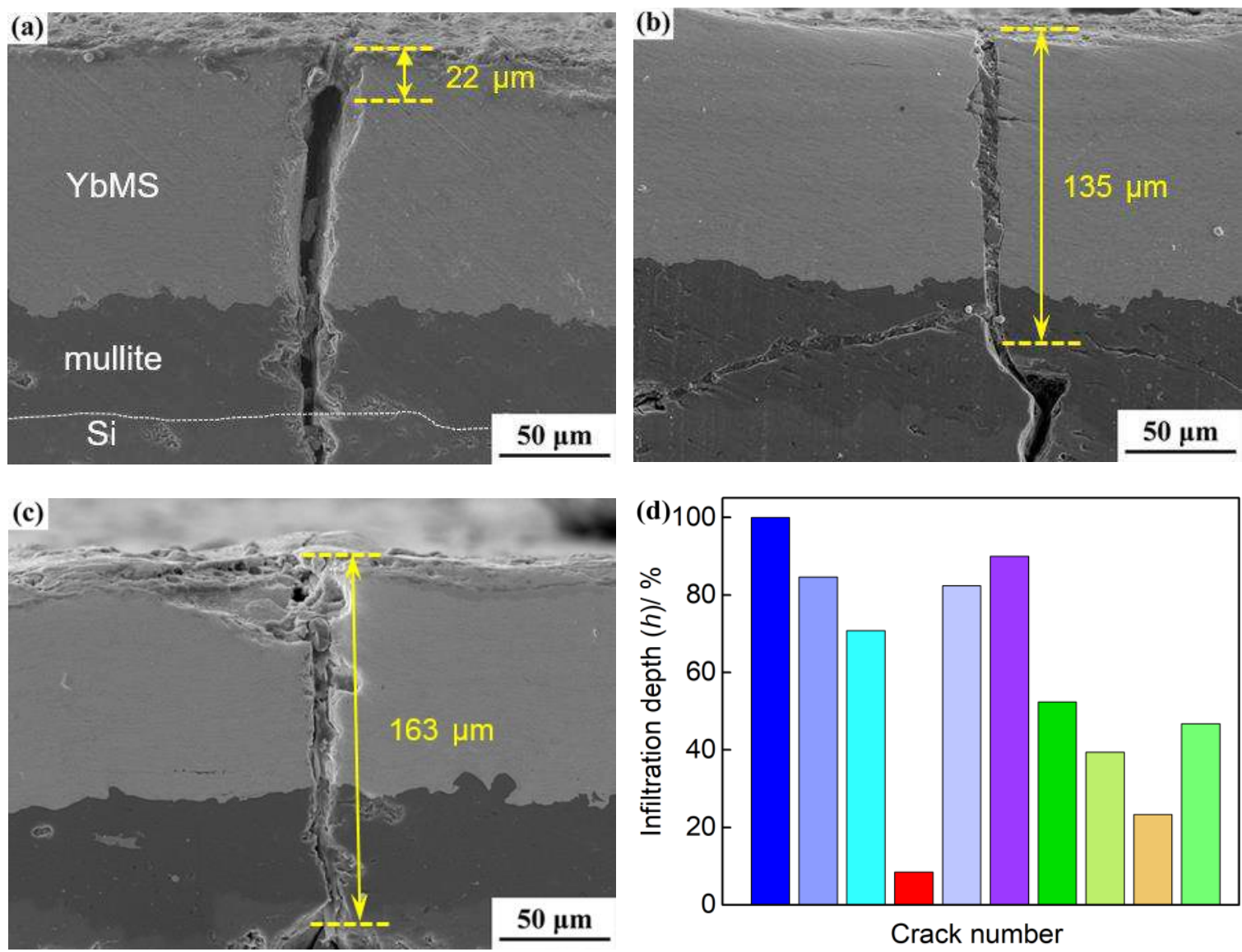

Fig. 4 Partially infiltrated pores under pressure-assisted infiltration at 20kPa: (a) infiltration stopped inside the top $\mathrm{Yb}_{2} \mathrm{SiO}_{5}$ layer; (b) infiltration stopped inside the middle mullite layer; (c) infiltration stopped inside the bottom Si layer; (d) statistical infiltration depths of ten randomly selected pores.
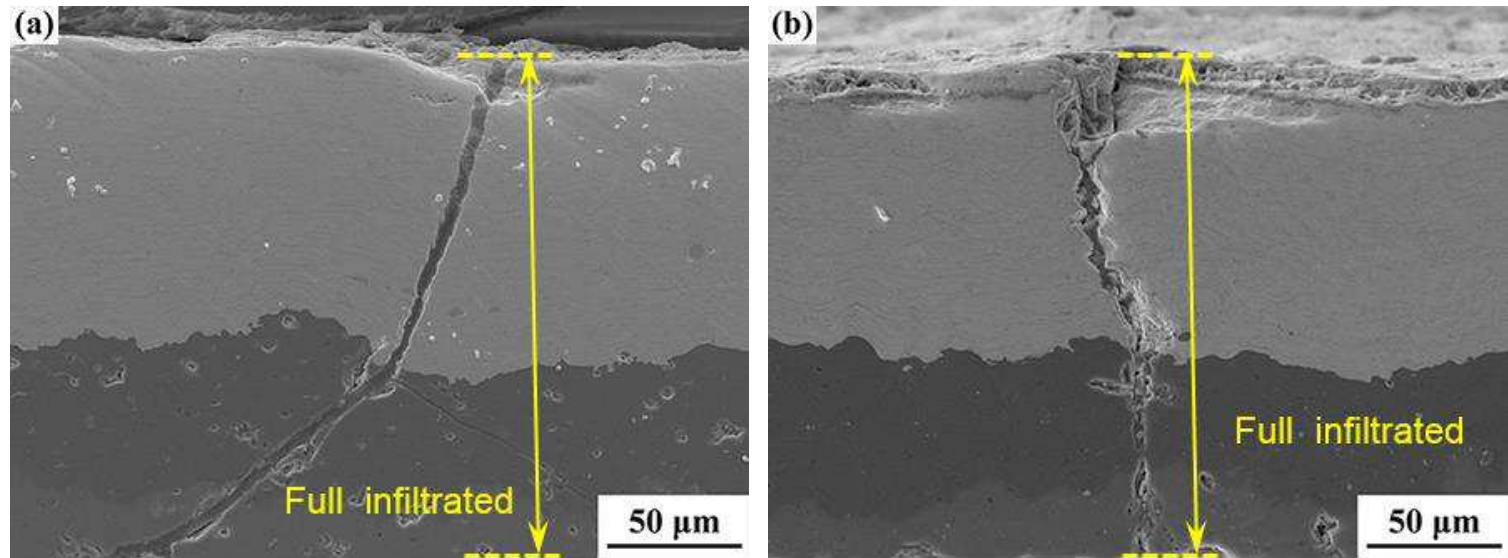

Fig. 5 Fully infiltrated pores under pressure-assisted infiltration at 100kPa: (a) regular pore with smooth and relatively parallel walls; (b) irregular pore with rough and zigzag walls. 

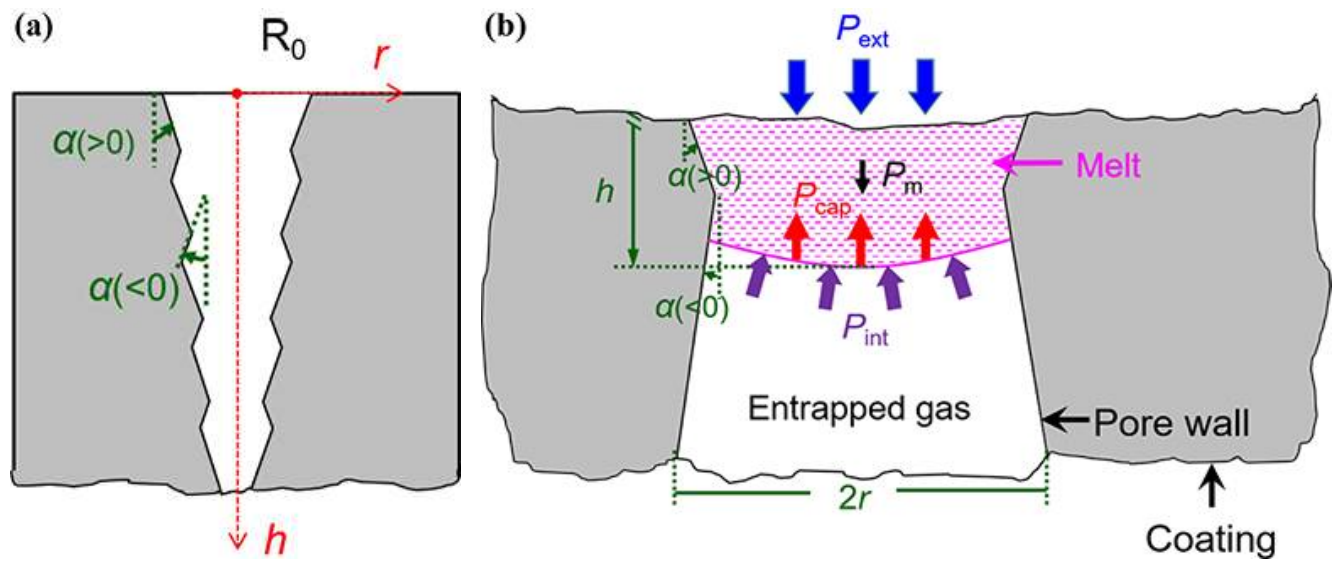

Fig. 6 Infiltration model in zigzag channel pore: (a) geometry model of channel pore with series converging and diverging structures and (b) physical model of melt infiltration, including four pressures that external gas pressure $\left(P_{\text {ext }}\right)$, internal gas pressure $\left(P_{\text {int }}\right)$, capillary pressure $\left(P_{\text {cap }}\right)$ induced by the curved surface of melt in microscale channels, and mass pressure $\left(P_{\mathrm{m}}\right)$ here is gravity.

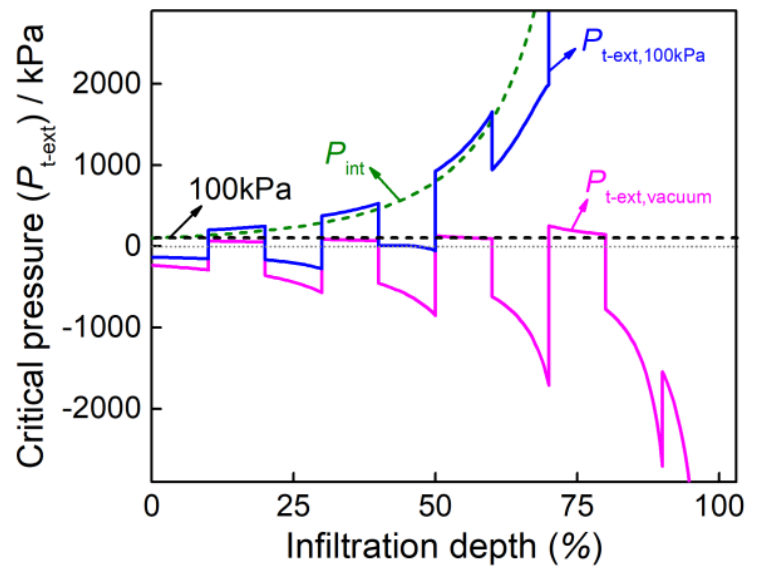

Fig. 7 Relationship between critical external pressures $\left(P_{\mathrm{t}-\mathrm{ext}}\right)$ and infiltration depth $(H)$ under different initial internal pressures: the blue line represents the value of $100 \mathrm{kPa}$, which is based on equation (5); the pink line represents the value of 0 , corresponding to equation (6). 


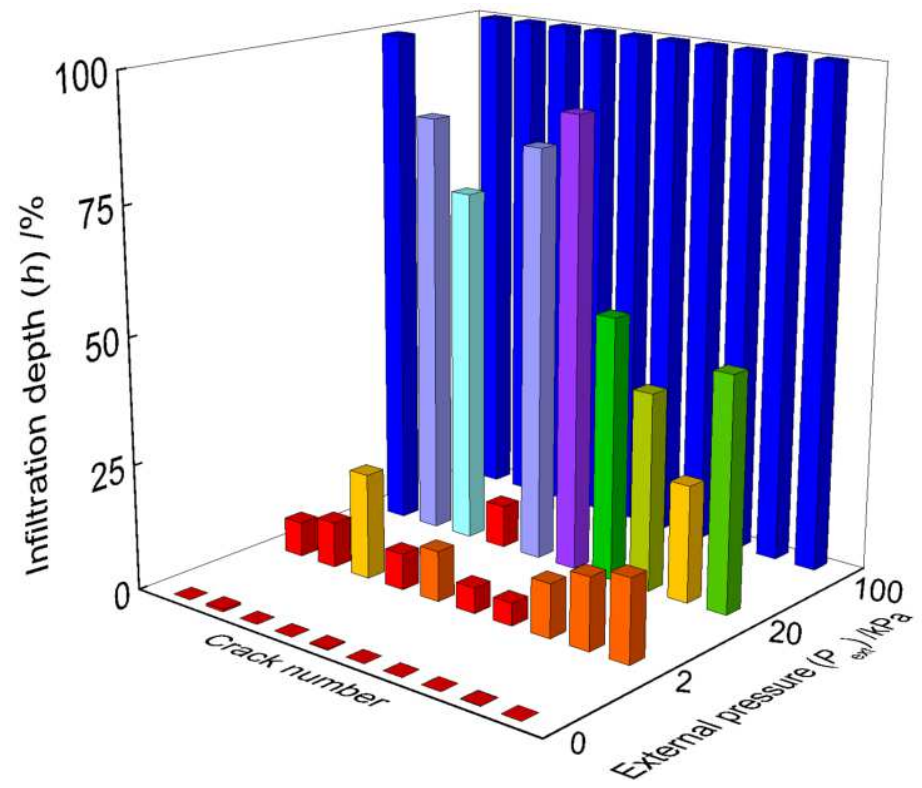

Fig. 8 Improved infiltration depths by increasing external pressures, which is statistically known from the infiltration results of selected 10 pores under each external pressure

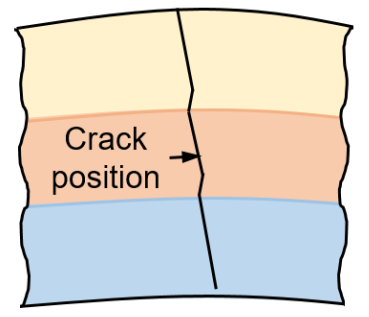

Theoretical crack position

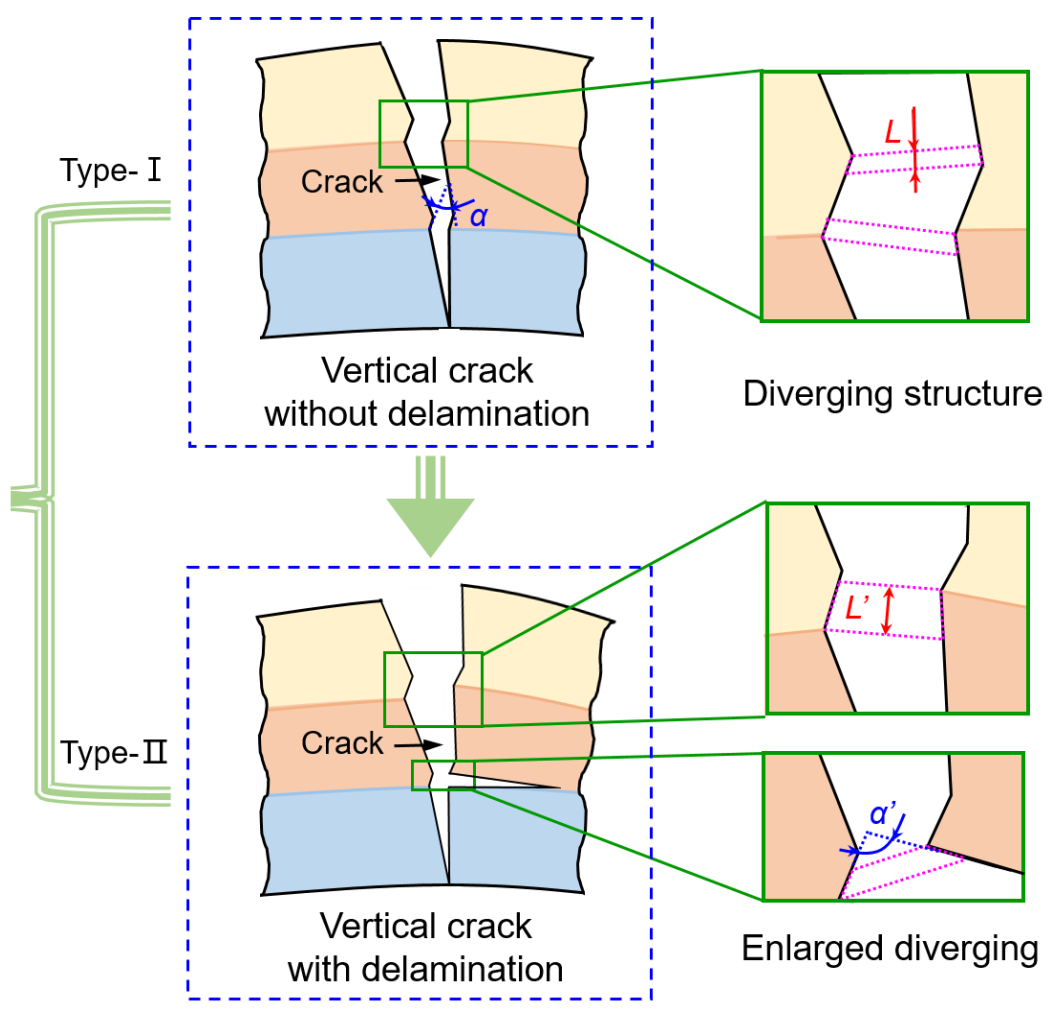

Fig. 9 Schematic diagram of the formation of zigzag morphology with converging and diverging structures 

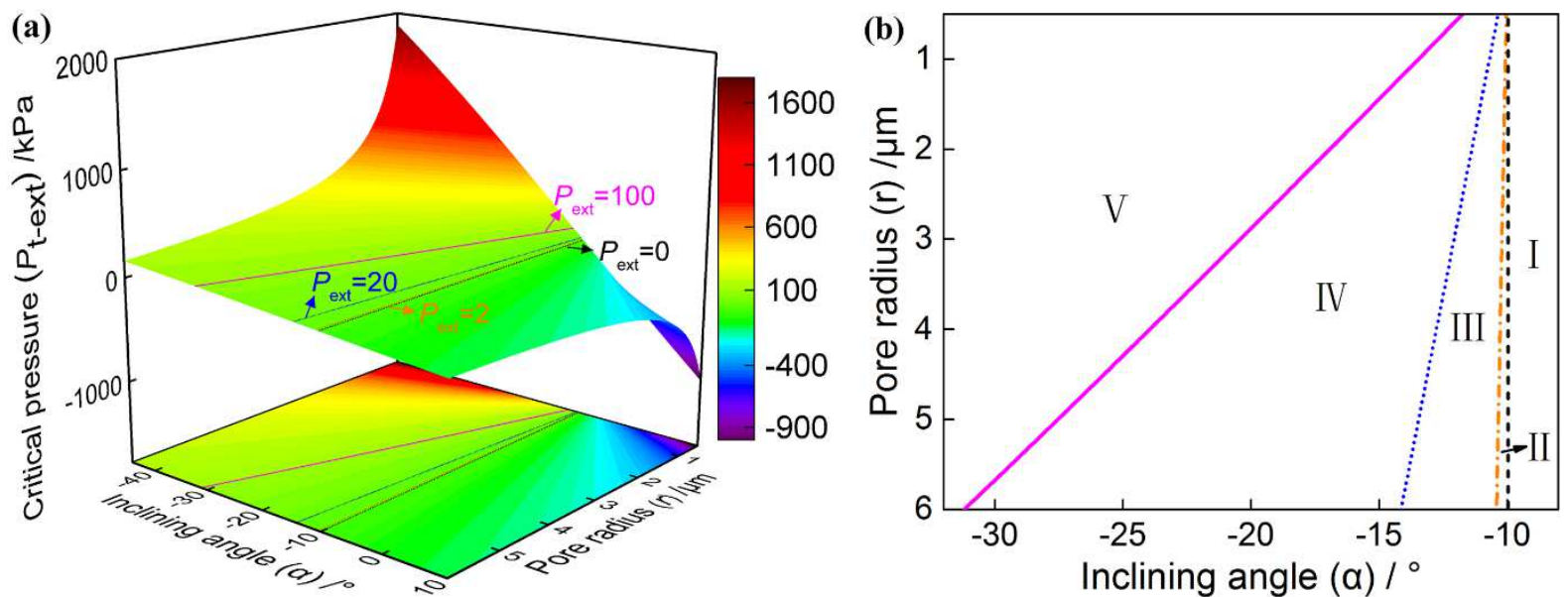

Fig. 10 (a) Critical pressure $\left(P_{\text {text }}\right)$ as a function of pore wall inclining angle $(\alpha)$ and pore radius $(r)$, as well as four isobars of experimental pressures that $0,2,20$, and $100 \mathrm{kPa}$; (b) the corresponding projection of the four isobars in Fig.10a, which divide the geometric parameters into five areas.
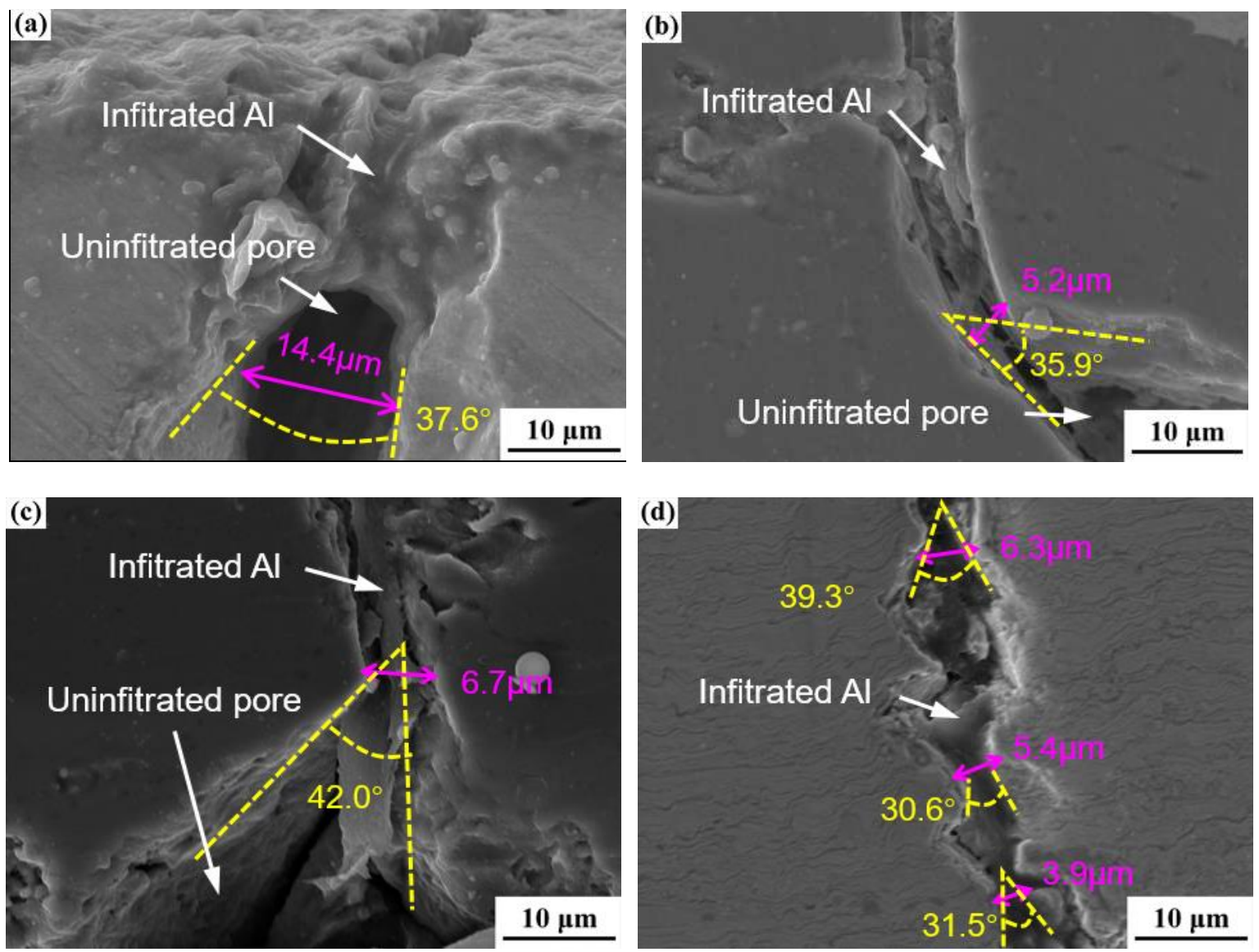

Fig. 11 Infiltration interface of partially infiltrated pores at pressure of (a)-(c) $20 \mathrm{kPa}$ and fully infiltrated pore at pressure of (d) $100 \mathrm{kPa}$. 

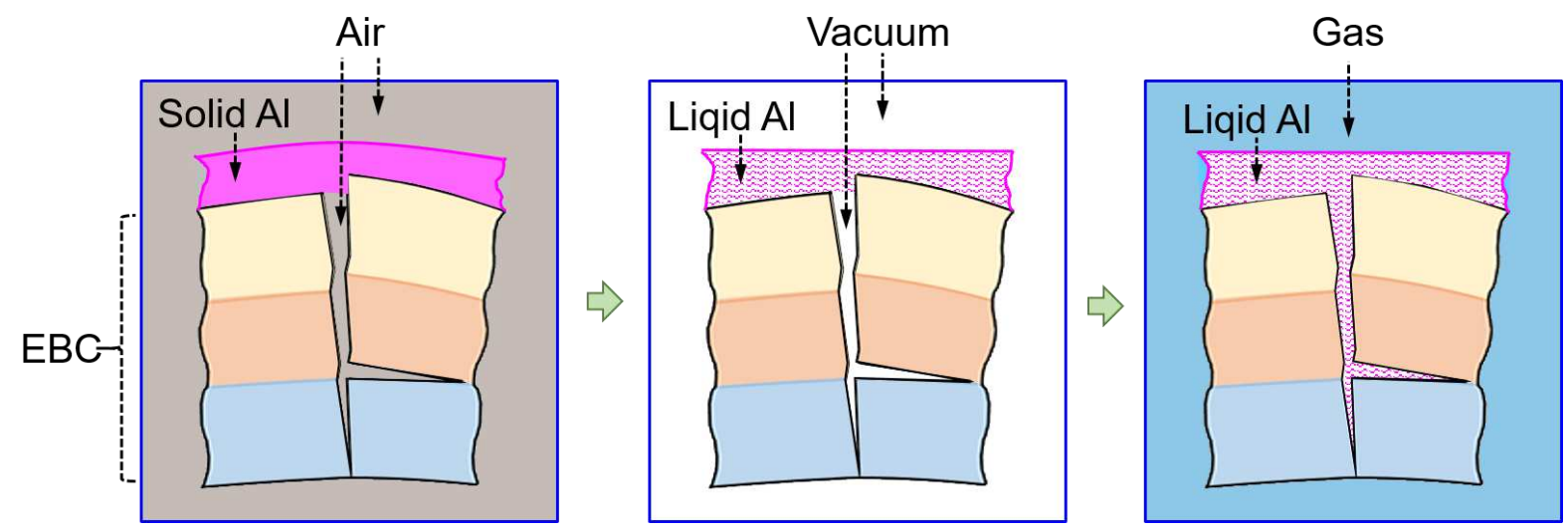

Fig. 12 Schematic diagram illustrates the steps of deep infiltration 


\section{Figures}
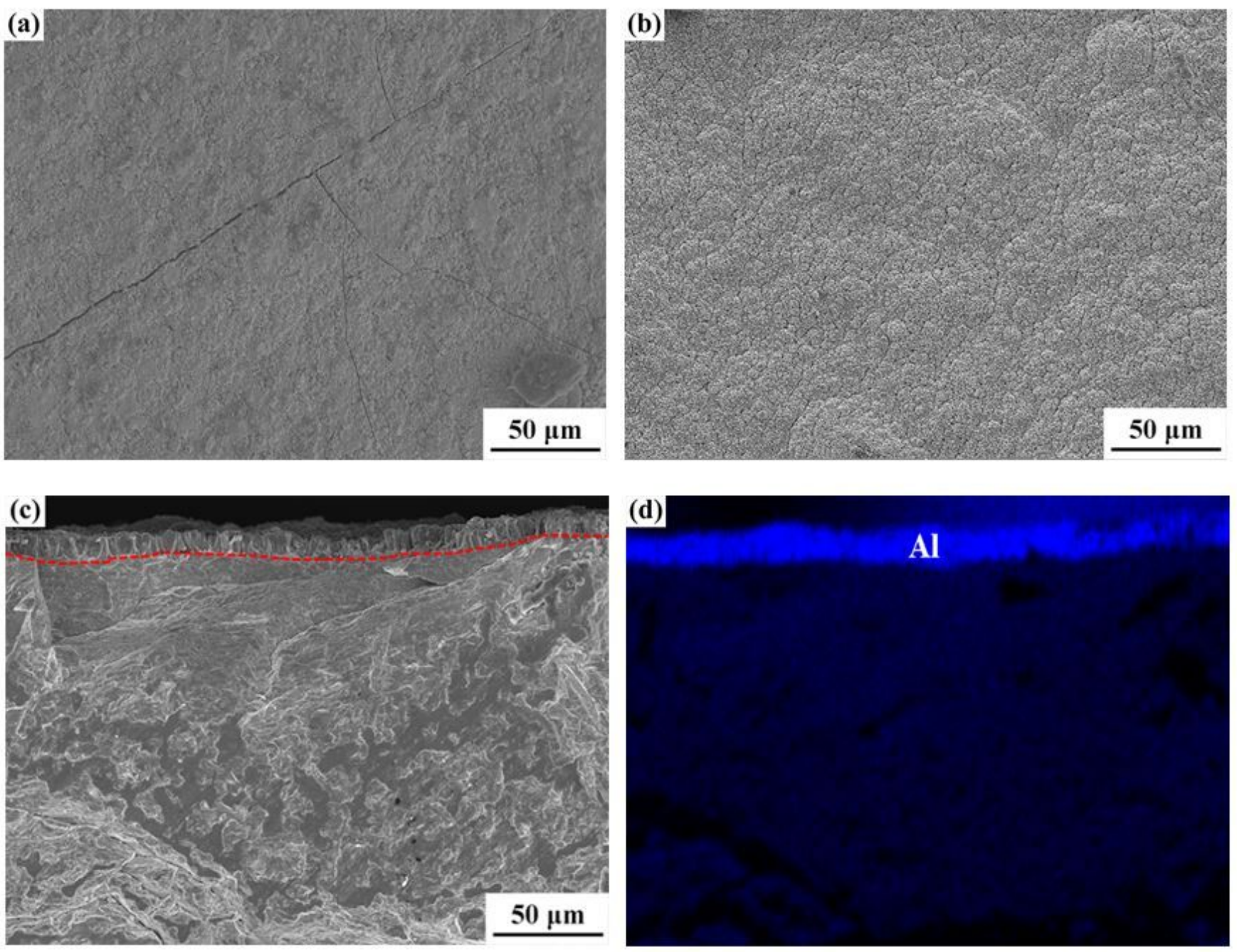

\section{Figure 1}

Microstructure of multiple-layer coatings before and after magnetron sputtering aluminum film: (a) asprayed surface of EBC; (b)(c) surface and cross-section microstructure after magnetron sputtering aluminum films, respectively; (d) element mapping of aluminum of Fig.1c. 

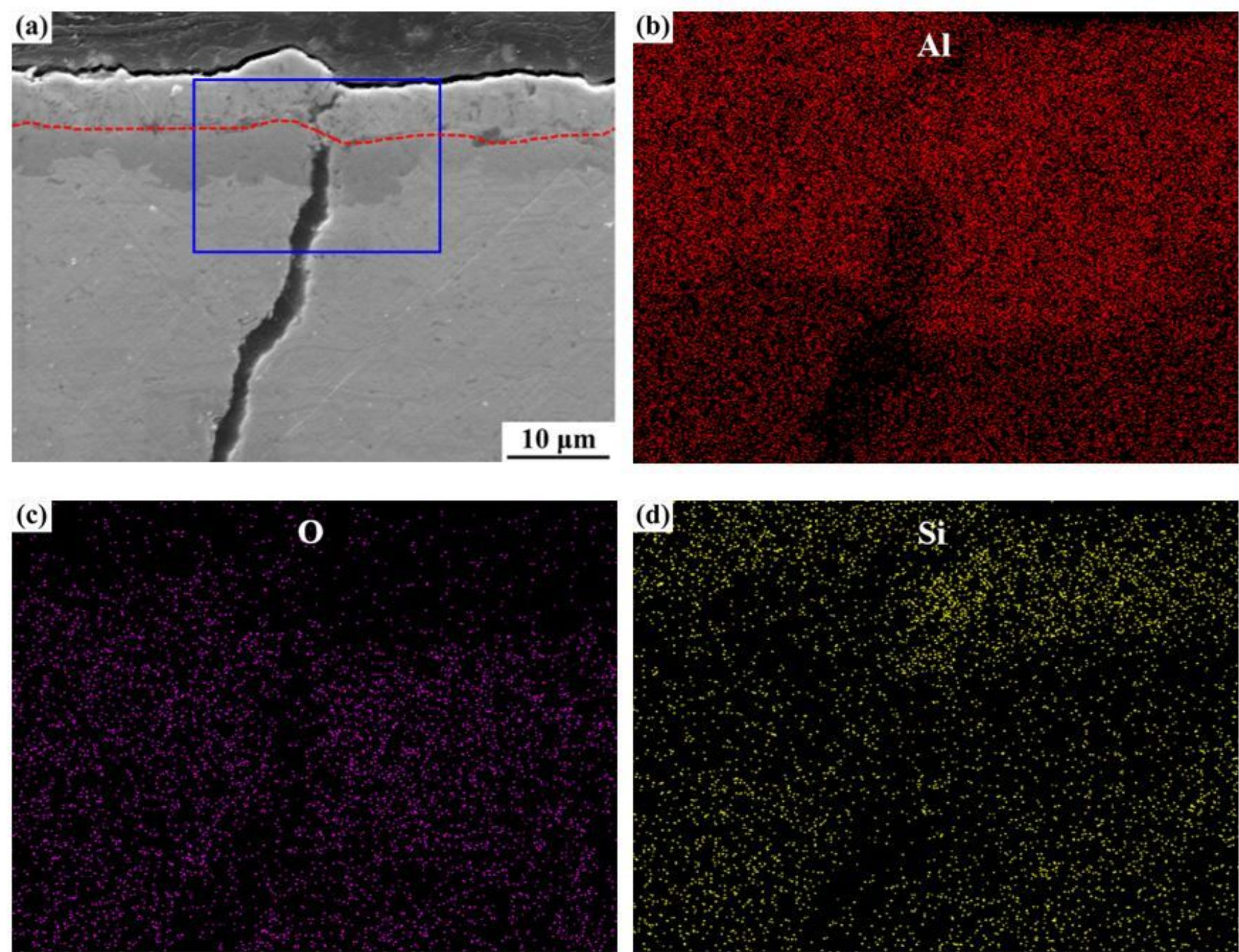

Figure 2

Uninfiltrated pores in EBC under vacuum infiltration (also known as spontaneous infiltration) of molten aluminum: (a) cross-section view of the pore; (b) - (d) Al, O, and Si element maps of the blue rectangle area in Fig.2a. 

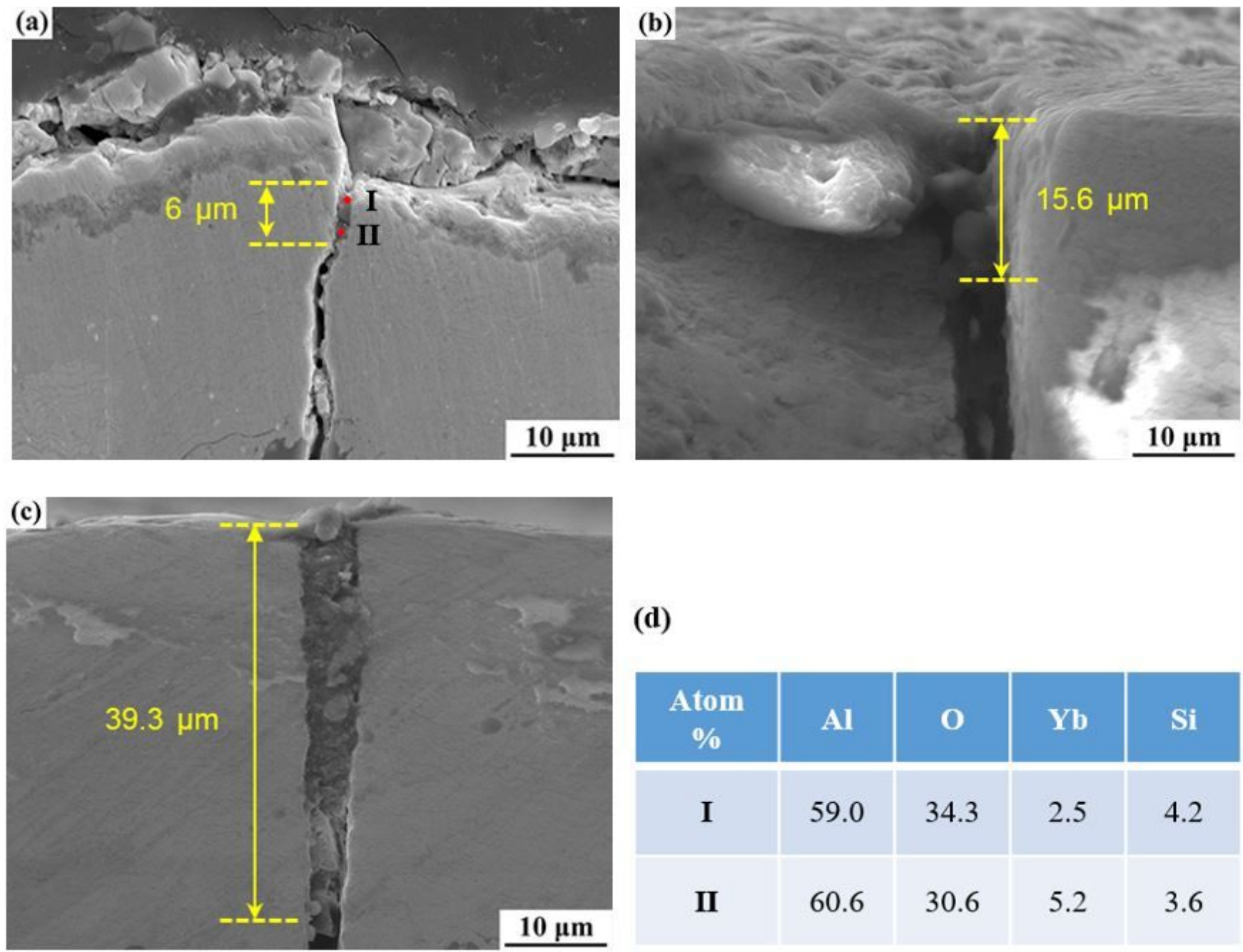

(d)

\begin{tabular}{|c|c|c|c|c|}
\hline $\begin{array}{c}\text { Atom } \\
\%\end{array}$ & Al & $\mathbf{0}$ & Yb & Si \\
\hline I & 59.0 & 34.3 & 2.5 & 4.2 \\
\hline II & 60.6 & 30.6 & 5.2 & 3.6 \\
\hline
\end{tabular}

Figure 3

Near-entrance infiltrated pores under pressure-assisted infiltration at 2kPa: (a)-(c) cross-section view of

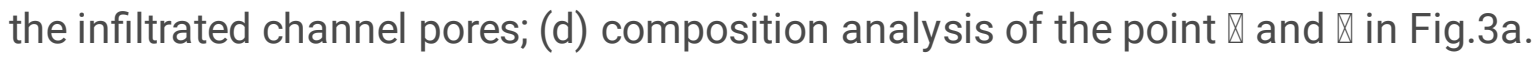



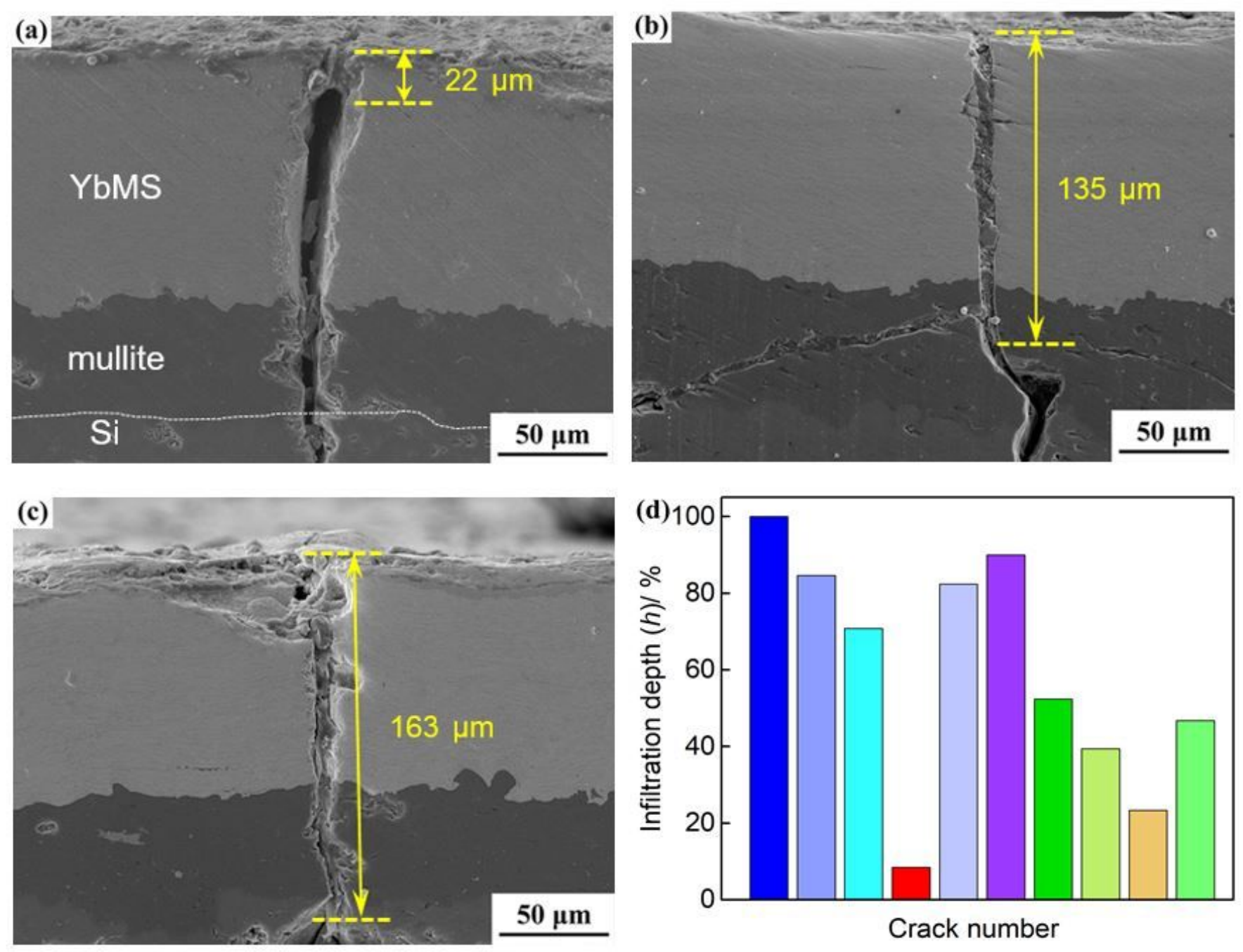

\section{Figure 4}

Partially infiltrated pores under pressure-assisted infiltration at 20kPa: (a) infiltration stopped inside the top Yb2Si05 layer; (b) infiltration stopped inside the middle mullite layer; (c) infiltration stopped inside the bottom Si layer; (d) statistical infiltration depths of ten randomly selected pores. 

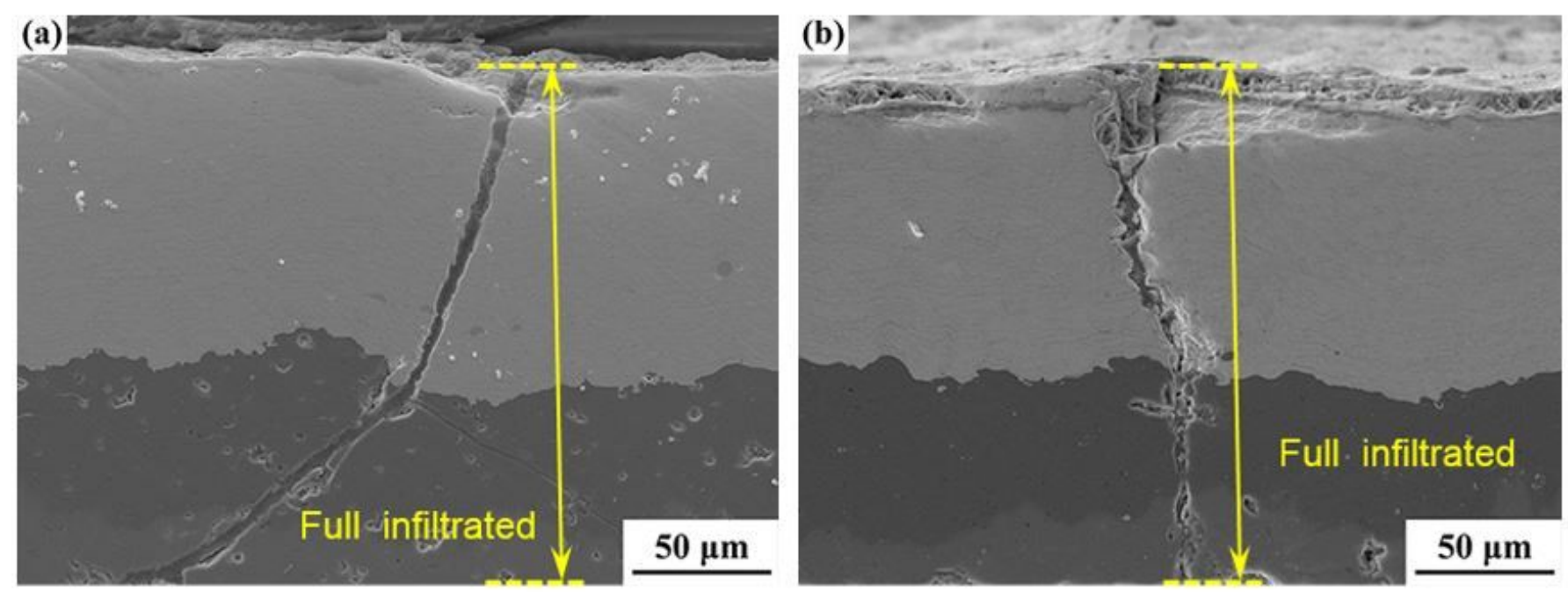

\section{Figure 5}

Fully infiltrated pores under pressure-assisted infiltration at $100 \mathrm{kPa}$ (a) regular pore with smooth and relatively parallel walls; (b) irregular pore with rough and zigzag walls.
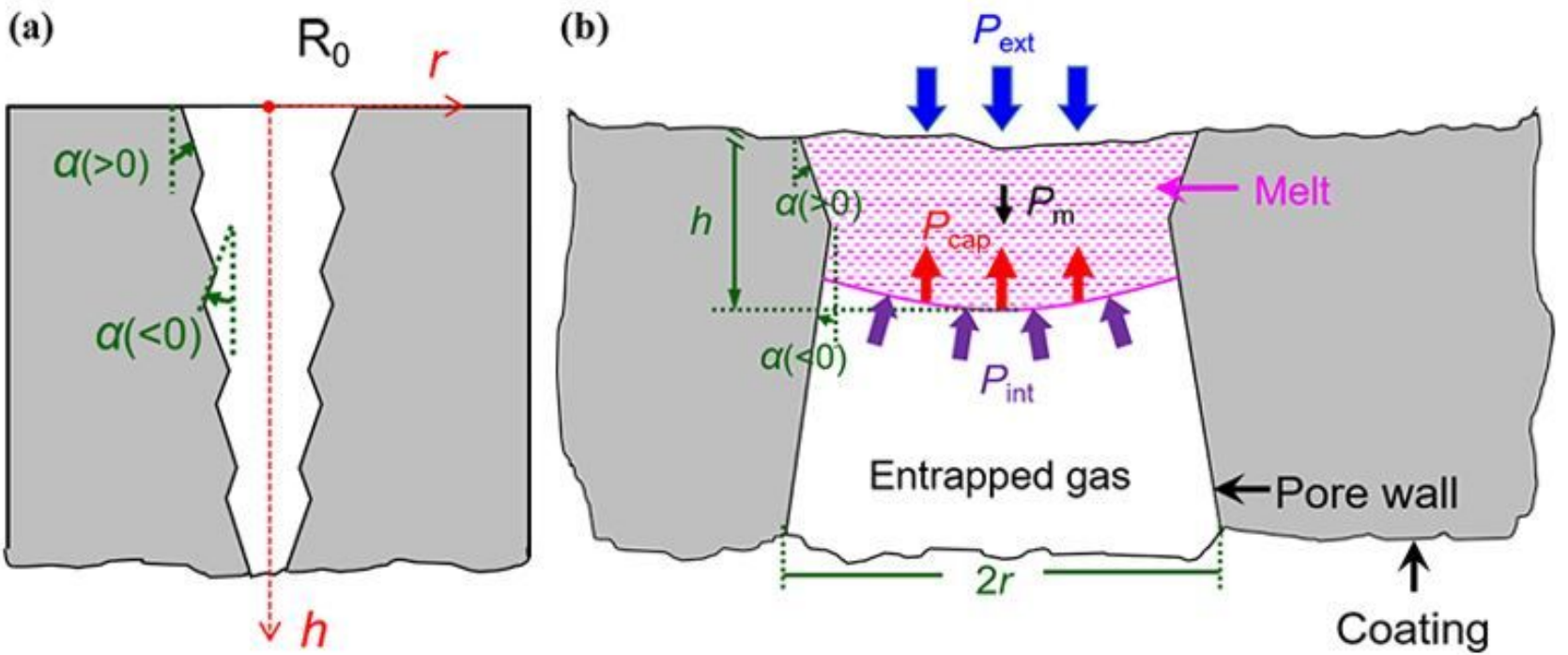

Figure 6

Infiltration model in zigzag channel pore: (a) geometry model of channel pore with series converging and diverging structures and (b) physical model of melt infiltration, including four pressures that external gas pressure (Pext), internal gas pressure (Pint), capillary pressure (Pcap) induced by the curved surface of melt in microscale channels, and mass pressure $(\mathrm{Pm})$ here is gravity. 


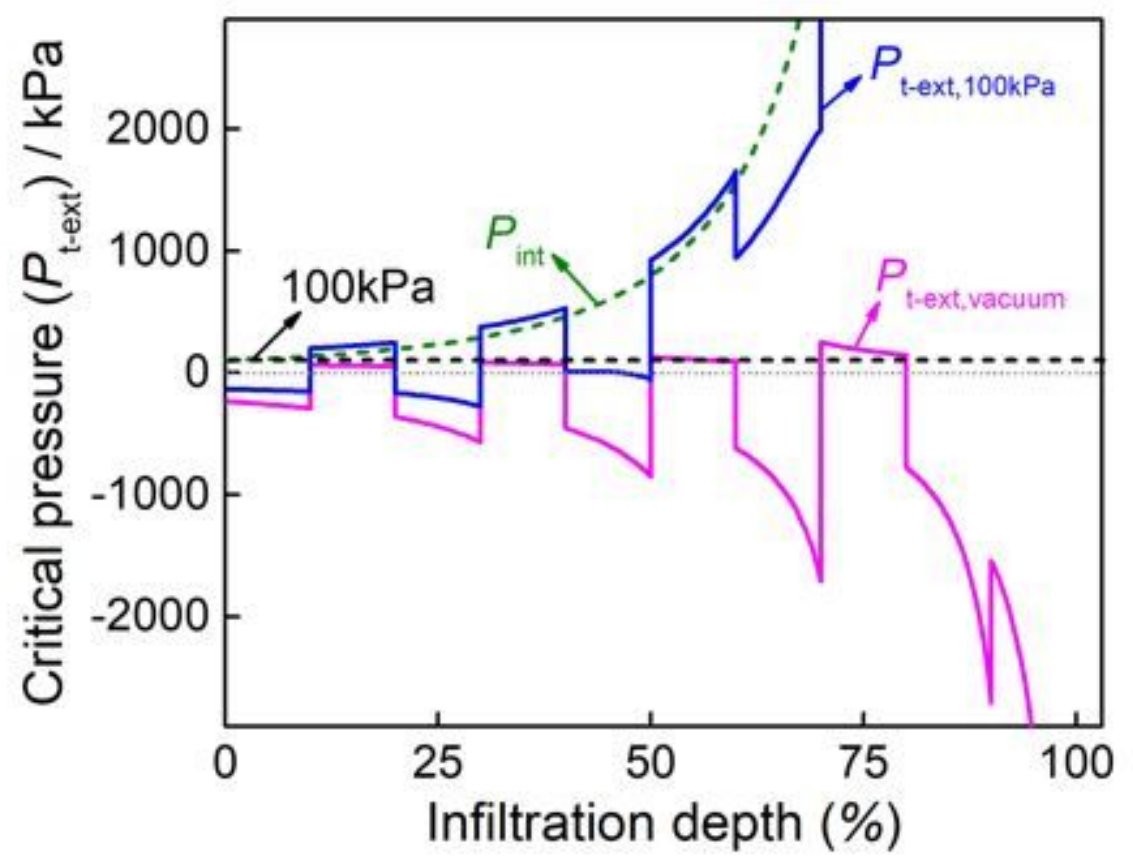

Figure 7

Relationship between critical external pressures (Pt-ext) and infiltration depth $(\mathrm{H})$ under different initial internal pressures: the blue line represents the value of $100 \mathrm{kPa}$, which is based on equation (5); the pink line represents the value of 0 , corresponding to equation (6). 


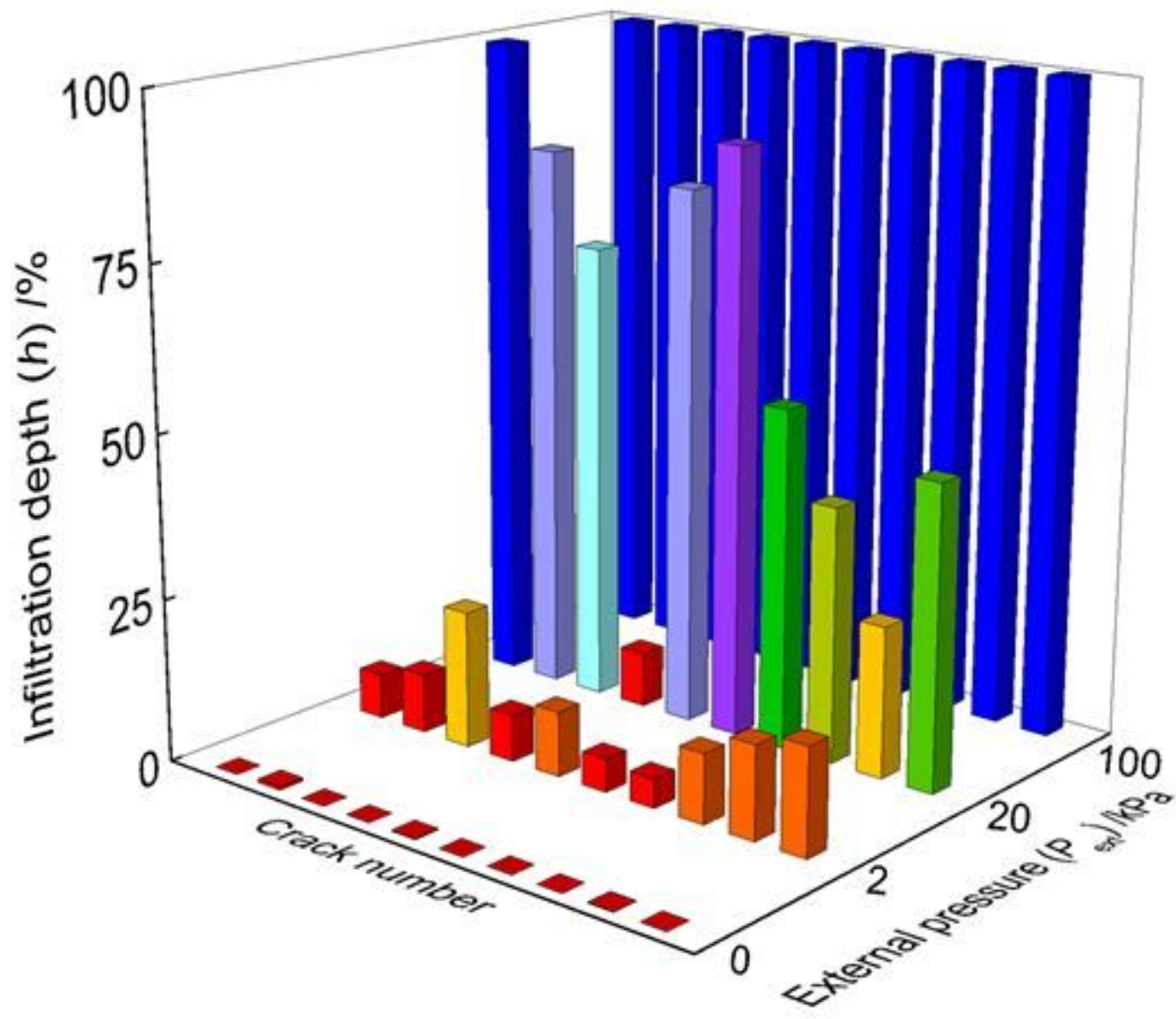

Figure 8

Improved infiltration depths by increasing external pressures, which is statistically known from the infiltration results of selected 10 pores under each external pressure 


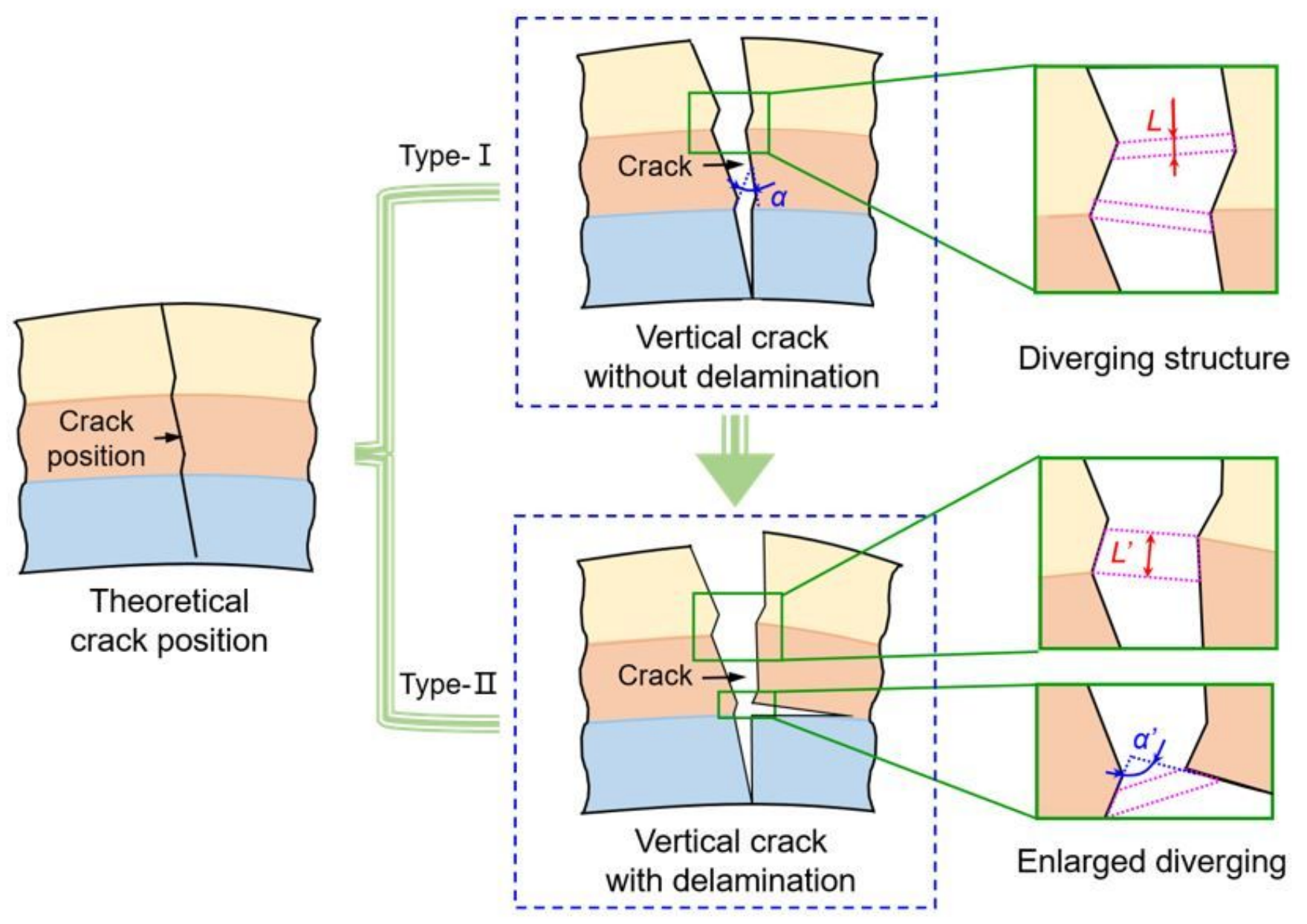

Figure 9

Schematic diagram of the formation of zigzag morphology with converging and diverging structures
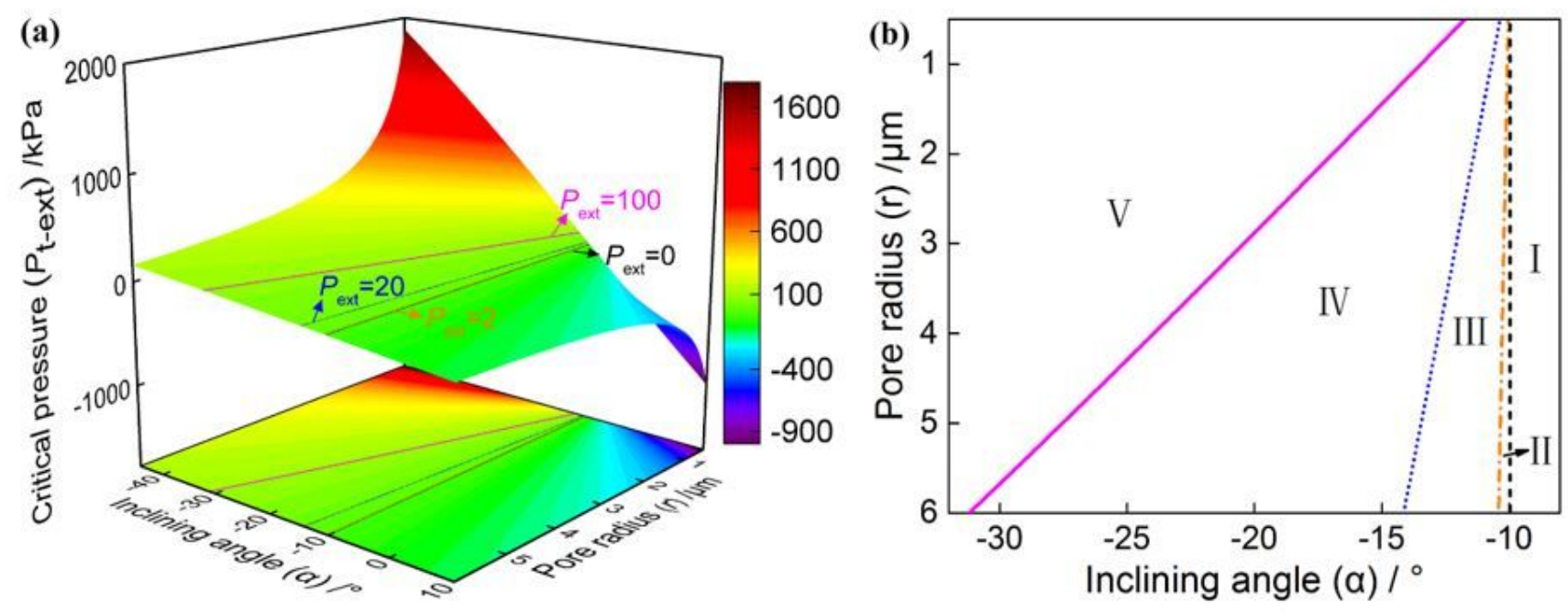

Figure 10 
(a) Critical pressure (Pt-ext) as a function of pore wall inclining angle (a) and pore radius ( $r$ ), as well as four isobars of experimental pressures that $0,2,20$, and $100 \mathrm{kPa}$; (b) the corresponding projection of the four isobars in Fig.10a, which divide the geometric parameters into five areas.
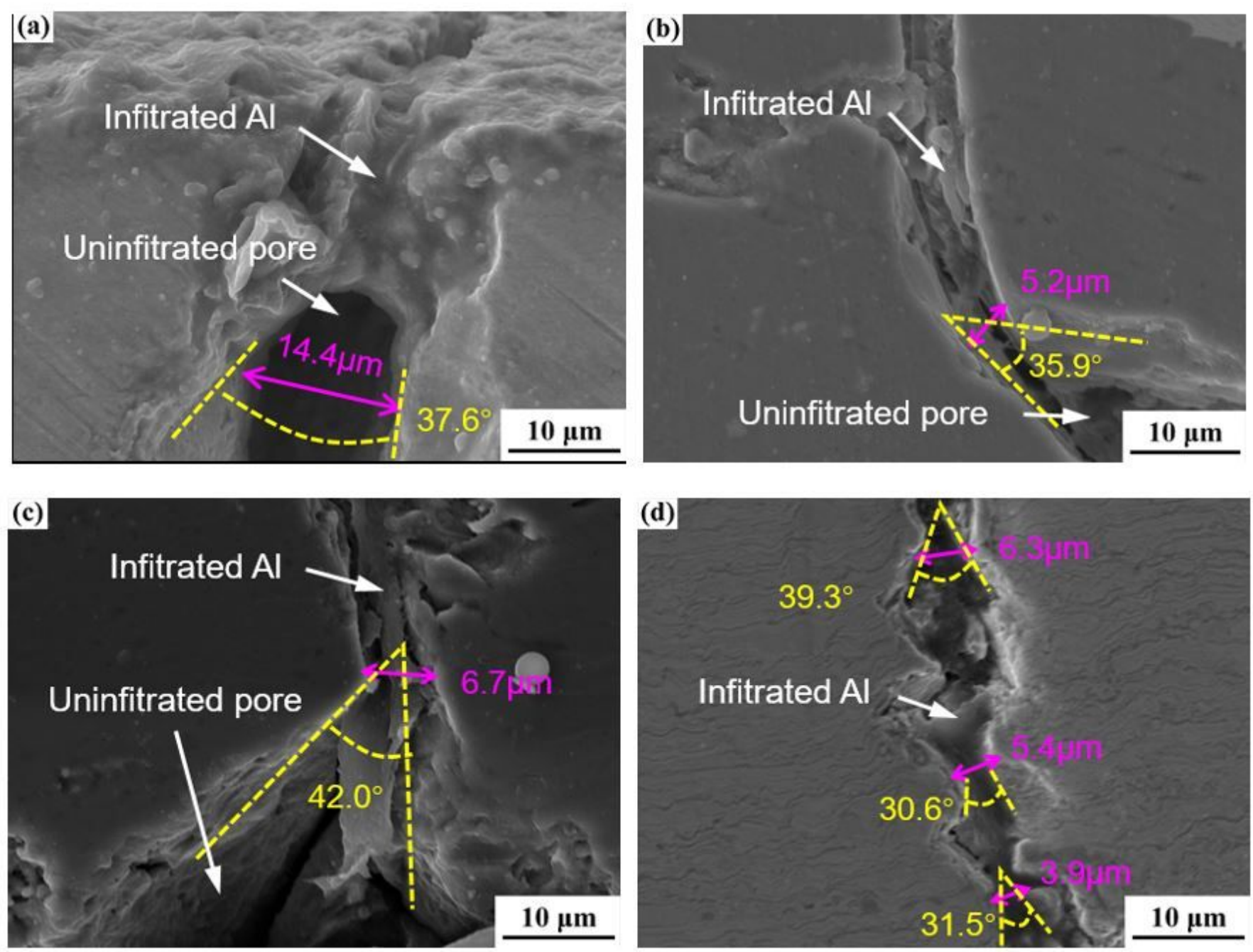

\section{Figure 11}

Infiltration interface of partially infiltrated pores at pressure of (a)-(c) $20 \mathrm{kPa}$ and fully infiltrated pore at pressure of (d) $100 \mathrm{kPa}$. 

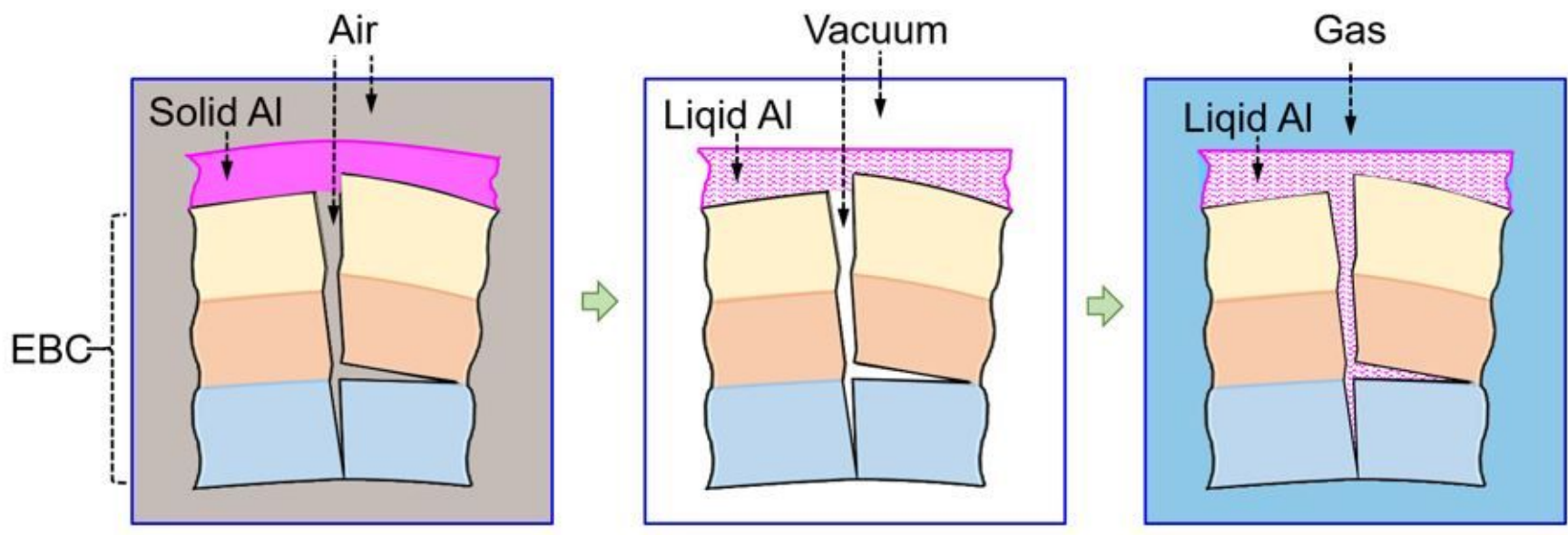

Figure 12

Schematic diagram illustrates the steps of deep infiltration 